\title{
IER2-induced senescence drives melanoma invasion through osteopontin
}

\author{
Lenka Kyjacova ${ }^{1}$, Rafael Saup ${ }^{1}$, Kerstin Rönsch ${ }^{1,2,6}$, Sabine Wallbaum², Stefanie Dukowic-Schulze (iD ${ }^{1,2}$, Amelia Foss (iD) ${ }^{1}$, \\ Sandra D. Scherer ${ }^{1,2}$, Melanie Rothley ${ }^{2}$, Antje Neeb ${ }^{2}$, Nicole Grau ${ }^{2,7}$, Wilko Thiele $\mathbb{D}^{1,2}$, Sonja Thaler ${ }^{1}$, Natascha Cremers ${ }^{2}$, \\ Carsten Sticht ${ }^{3}$, Norbert Gretz ${ }^{3}$, Boyan K. Garvalov (iD) ${ }^{1}$, Jochen Utikal (iD) ${ }^{4,5}$ and Jonathan P. Sleeman (iD) ${ }^{1,2}$
}

(c) The Author(s) 2021

Expression of the immediate-early response gene IER2 has been associated with the progression of several types of cancer, but its functional role is poorly understood. We found that increased IER2 expression in human melanoma is associated with shorter overall survival, and subsequently investigated the mechanisms through which IER2 exerts this effect. In experimental melanoma models, sustained expression of IER2 induced senescence in a subset of melanoma cells in a p53/MAPK/AKT-dependent manner. The senescent cells produced a characteristic secretome that included high levels of the extracellular phosphoglycoprotein osteopontin. Nuclear localization of the IER2 protein was critical for both the induction of senescence and osteopontin secretion. Osteopontin secreted by IER2-expressing senescent cells strongly stimulated the migration and invasion of non-senescent melanoma cells. Consistently, we observed coordinate expression of IER2, p53/p21, and osteopontin in primary human melanomas and metastases, highlighting the pathophysiological relevance of IER2-mediated senescence in melanoma progression. Together, our study reveals that sustained IER2 expression drives melanoma invasion and progression through stimulating osteopontin secretion via the stochastic induction of senescence.

Oncogene (2021) 40:6494-6512; https://doi.org/10.1038/s41388-021-02027-6

\section{INTRODUCTION}

The term "immediate-early response" (IER) describes the collective transient expression of immediate-early genes (IEGs) upon exposure to a variety of extracellular cues, including growth factors, mitogens, and stressors such as ultraviolet (UV) irradiation and toxins [1,2]. Constitutive IEG expression, for example, caused by disturbed mitogen-activated protein kinase (MAPK) signaling that is often found in cancer cells, is associated with tumor progression and metastasis [3-5].

The immediate early response protein 2 (IER2, also called ETR101 and CHX1 in humans or Pip92 in the mouse; hereafter referred to as IER2, regardless of species) is a poorly investigated IEG that is rapidly but transiently induced in response to a variety of growth factors, and other mitogenic and differentiationinducing stimuli [6-9]. The IER2 protein is short-lived due to multiple PEST sequences, contains a putative bipartite nuclear localization signal (NLS), and has limited homology to JunB and JunD $[9,10]$. IER2 possesses no obvious DNA-binding motif but has been implicated in transcriptional regulation [11]. IER2 has also been suggested to regulate the activity of the protein phosphatase PP2A [12]. Cell density influences the subcellular localization of the IER2 protein, and the release of cells from contact inhibition results in translocation of IER2 from the cytoplasm to the nucleus [13]. During embryonic development, IER2 plays a role in determining left-right asymmetry [14].

We previously reported that IER2 is aberrantly and constitutively expressed in a wide variety of human tumors in comparison to the corresponding non-transformed tissue. Ectopic overexpression of IER2 in poorly metastatic pancreatic tumor cells promoted their motility and invasiveness in vitro and stimulated metastasis in vivo. Consistently, we found that IER2 is a predictor of poor metastasis-free and overall survival of colorectal adenocarcinoma patients [13]. More recently, others have demonstrated a critical role for IER2 in the regulation of hepatocellular carcinoma migration and invasion via an integrin $\beta 1$-focal adhesion kinase (FAK)-Src-paxillin signaling pathway and Rho GTPases [15-17], and in the regulation of endothelial cell motility, cell-matrix adhesion and in vitro angiogenesis [18]. To date, however, the association between IER2 expression and tumor progression has not been explained mechanistically, in particular the consequence of the constitutive rather than transient expression that is observed in many cancers.

Here, we report that sustained expression of IER2 in fibroblasts stochastically induces cellular senescence. Senescence is typified by durable cell cycle arrest and an enlarged flattened morphology. The development of senescence involves proliferative arrest in





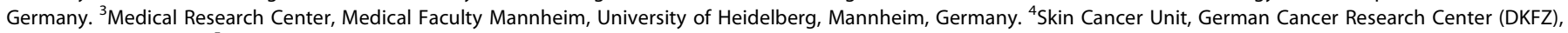

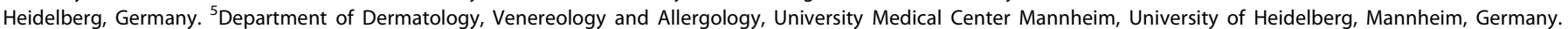


Germany. ${ }^{\bowtie}$ email: jonathan.sleeman@medma.uni-heidelberg.de
} 
response to sustained and robust activation of the $\mathrm{p} 16^{\mathrm{INK} 4 \mathrm{a}}-\mathrm{Rb}$ (retinoblastoma) and/or p53-p21 WAF1/CIP1 tumor suppressor pathways $[19,20]$. Features of senescent cells include an enlarged morphology, positivity for senescence-associated $\beta$-galactosidase, increased ploidy, and the secretion of a cocktail of proinflammatory cytokines, growth factors and matrix remodeling enzymes termed the senescence-associated secretory phenotype (SASP) [21]. The specific content of the SASP depends on the cell type and the senescence inducer $[22,23]$.

In the context of cancer, cellular senescence can both restrict and promote tumorigenesis and progression. On the one hand, it represents a first-line barrier against neoplastic transformation and tumor initiation $[19,24,25]$. On the other hand, senescence can stimulate tumor growth and progression through cellautonomous effects such as increasing invasive, tumorigenic, and cancer cell stemness properties [26, 27], as well as through non-cell-autonomous effects mediated by the SASP [28], including the recruitment of immature myeloid cells [29] and the promotion of metastasis [30].

In the present study, we report that IER2 expression can be constitutively increased in human melanomas and that this correlates with poor overall survival. By mimicking this constitutive expression in experimental models, we show that similar to the situation in fibroblasts, IER2 induces p53-dependent senescence in a fraction of melanoma cells and that this is associated with a characteristic SASP. A major component of the IER2-driven SASP is osteopontin (OPN), which plays a central role in driving melanoma cell invasion. These findings reveal an important role for IER2 in melanoma progression, highlight the role of senescence and the SASP in this process, and identify potential targets for therapeutic intervention.

\section{RESULTS}

\section{IER2 induces senescence in murine 3 T3 fibroblasts}

To investigate the impact of sustained IER2 expression on cell behavior, we engineered mouse 3T3 fibroblasts to inducibly express IER2 in response to RheoSwitch ligand 1 (RSL-1; hereafter referred to as RSL), a pharmacologically inert diacylhydrazine [31-33]. IER2 induction against very low basal levels was achieved after stimulation of the cells with RSL (Figs. S1a, 1a, 1b), which reached maximum expression at $6 \mathrm{~h}$ and diminished to basal levels within $48 \mathrm{~h}$ (Fig. 1c). To maintain IER2 expression over periods exceeding $24 \mathrm{~h}$, cells were therefore treated daily with RSL (Fig. S1b). While sustained RSL-driven IER2 expression had no effect on viability (Fig. S1c), striking morphological changes and cell division abnormalities reminiscent of cellular senescence were observed in a subset of 3 T3 cells (Video S1). Consistently, induction of IER2 expression resulted in increased senescenceassociated $\beta$-galactosidase activity in a portion of the cells (Fig. $1 \mathrm{~d}$, e), which is a marker of cellular senescence [34]. Furthermore, IER2-expressing cells accumulated in the G2/M phase of the cell cycle and exhibited elevated ploidy (Fig. 1f), again indicative of the induction of senescence.

To understand the transcriptional response to continuous IER2 expression, we performed differential gene expression profiling of RSL-treated IER2-inducible 3T3 cells relative to controls. Gene set enrichment analysis (GSEA) [35] using Kyoto encyclopedia of genes and genomes (KEGG) and gene ontology biological processes annotations revealed that IER2-induced genes are involved in processes, including lipid metabolism, immune/ inflammatory, cytokine production, and cell cycle regulation (Table S1). Importantly, the expression of TRP53 (mouse homolog of p53), the main regulator of senescence-associated cell cycle arrest [36], was increased, together with the p53 signaling pathway gene set. Correspondingly, expression of MDM2, a negative regulator of p53 [37] was decreased (Fig. 1g). In addition, several SASP-associated factors [28] including IL-6, CCL8, CXCL1, CXCL5, CCL3, and CCL11 were induced in response to IER2, together with SAA1, which has been reported to amplify the expression of SASP-related factors via the Toll-like receptors TLR2/ TLR4 [38] (Fig. 1h). Western blotting confirmed increased expression of p53 in IER2-expressing 3T3 cells, as well as of the p53-target gene p21 ${ }^{\text {waf1/cip } 1}$ (hereafter p21) (Fig. 1i). In wild-type UV-irradiated 3T3 cells, IER2 induction preceded p53 activation (Fig. S1d) and was required for p53 stabilization (Fig. S1e).

Together, these findings demonstrate that constitutive IER2 expression stochastically promotes senescence in mouse fibroblasts, and point to a potential functional relationship between IER2 and p53.

\section{Constitutive IER2 expression correlates with poor prognosis in melanoma}

Melanoma has high intrinsic potential for dissemination [39] and a high rate of metastatic spread compared to other cancers [40]. IER2 promotes metastasis and is associated with poor prognosis in colorectal cancer patients [13]. To investigate whether IER2 might play a similar role in human melanoma, we analyzed the TCGA skin cutaneous melanoma dataset. Kaplan-Meier analysis revealed that melanoma patients with high IER2 expression (Fig. S2a) had a significantly shorter overall survival compared to patients with lower IER2 levels (Fig. 2a). To analyze whether high IER2 expression is linked to common driver mutations in melanoma [41], tumors were stratified based on their BRAF, NRAS, and TP53 mutation status. In line with the mutual exclusivity of BRAF and NRAS mutations in melanoma [42], we found that high IER2 expression is associated with wild-type BRAF and mutated NRAS. Importantly, high IER2 expression was almost exclusively associated with wild-type p53 status (Fig. 2b), consistent with our findings that p53 levels are increased in melanoma cells upon sustained IER2 expression (see below).

To determine whether IER2 expression correlates with the proliferative or the invasive potential of melanoma cells, we analyzed a dataset of human melanoma cell lines utilizing the Heuristic Online Phenotype Prediction algorithm (HOPP) [43-45]. This revealed significantly higher IER2 expression in melanoma cells that exhibited an intermediate or invasive phenotype (Fig. S2b, Table S2). Thus, similar to our previous work with pancreatic tumor cells [13], IER2 expression is associated with enhanced invasiveness of melanoma cells.

\section{IER2 stochastically induces senescence in melanoma cells via the p53-p21 axis}

To investigate the impact of constitutive IER2 expression in melanoma, we generated IER2-inducible RheoSwitch B16-F10 (B16) and Ret mouse melanoma cells, which both harbor wildtype p53 (p53 ${ }^{\mathrm{WT}}$ ) and express only very low levels of IER2. To control for the effect of p53 status, in the absence of a suitable melanoma cell line we similarly created IER2-inducible 67NR mouse breast adenocarcinoma cells, which are p53-deficient (Fig. S2c) and likewise express very low endogenous levels of IER2 (Fig. 2c). To achieve sustained IER2 expression over periods exceeding $24 \mathrm{~h}$, cells were treated with RSL daily (Fig. S2d). Similar to the case with fibroblasts, induction of IER2 expression in B16 and Ret cells led to the development of senescence in a proportion of the cells (Fig. 2d, e), as well as to the accumulation of cells in the G2/M phase of the cell cycle, and to a higher number of $>4 \mathrm{~N}$ polyploid cells (Fig. S2e). By contrast, the p53deficient ( $\left.\mathrm{p} 53^{\text {null }}\right)$ 67NR cells remained unaffected by IER2 overexpression (Fig. 2d, e). Importantly, ectopic re-introduction of wild-type p53 into two independent IER2-inducible 67NR clonal cell lines enhanced the ability of IER2 to induce senescence (Fig. S2f-h), indicating that wild-type p53 is required for the efficient induction of senescence by IER2. 


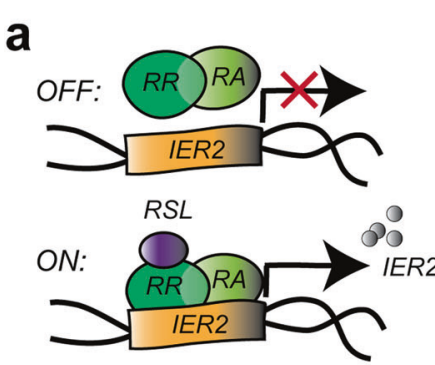

d
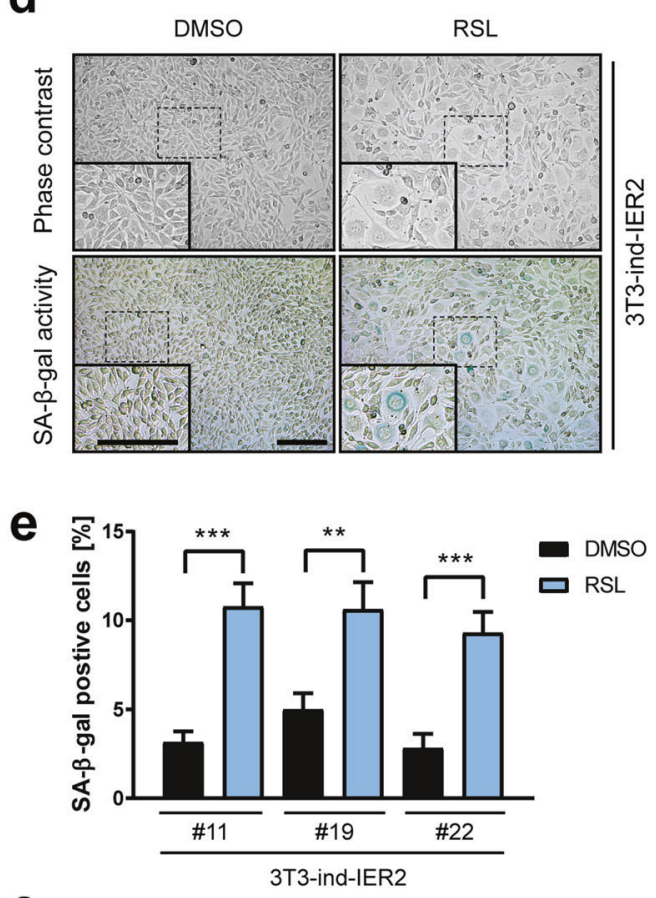

f

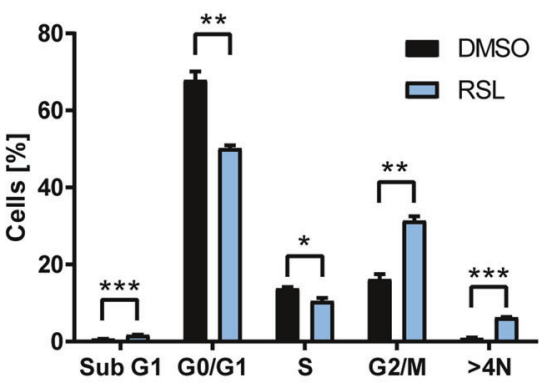

i

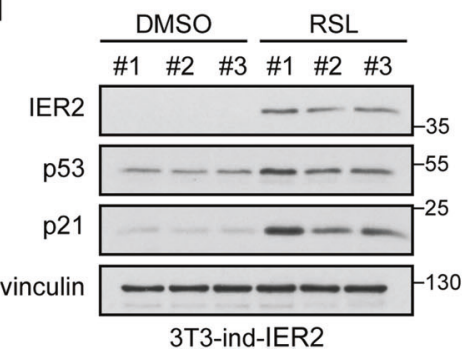

In concordance with the results obtained with mouse 3T3 fibroblasts, ectopic expression of IER2 in B16 cells led to p53 stabilization and activation, as evidenced by phosphorylation of p53 on serine 15 and 392. Consistently, IER2 expression resulted in accumulation of the $48 \mathrm{kDa}$ MDM2 isoform (MDM2-iso), an g



h
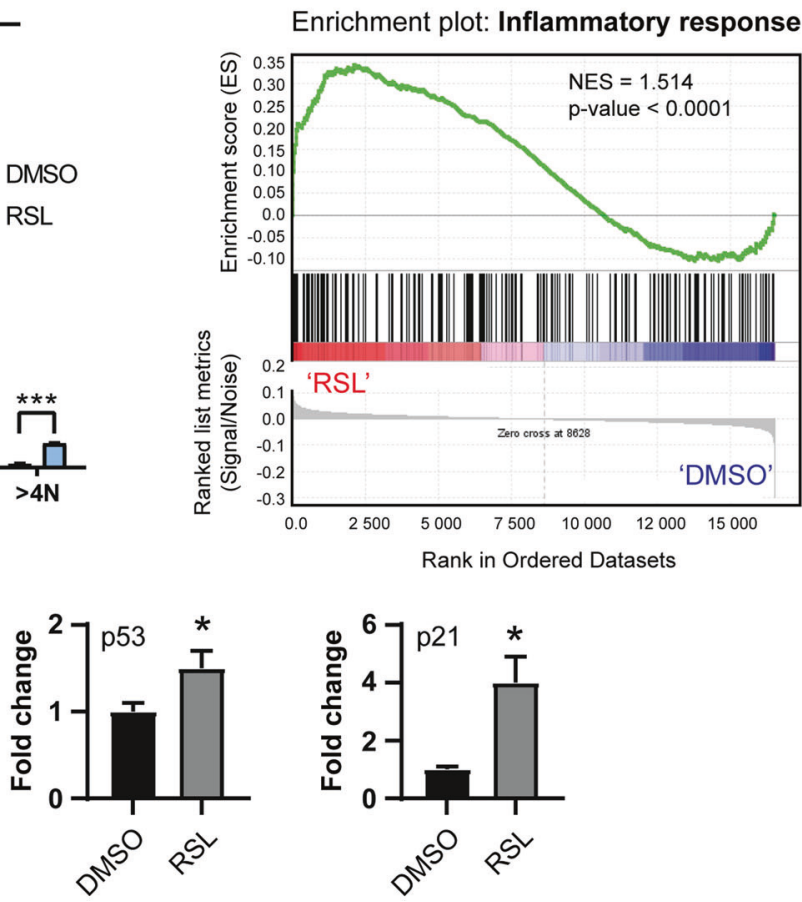

3T3-ind-IER2 DMSO RSL



3T3-ind-IER2 DMSO RSL

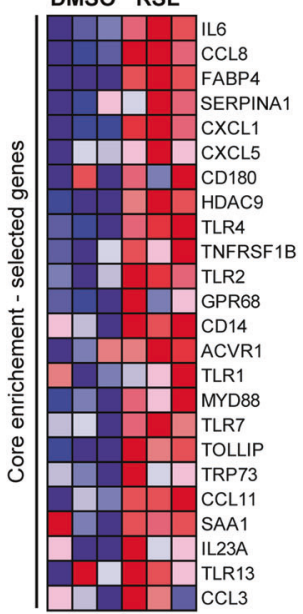

$\square$ Upregulated

Downregulated
MDM2 splice variant that stabilizes/activates p53 through competitive binding to MDM2-full length (MDM2-FL), which inhibits the MDM2-FL-p53 interaction and thereby reduces p53 degradation [46-48]. Moreover, the p53 target gene and cell cycle regulator $\mathrm{p} 21$, together with $\mathrm{p} 27^{\mathrm{K} I \mathrm{P} 1}$ (p27) were also elevated 
Fig. 1 IER2 induces senescence in murine 3T3 fibroblasts. a Schematic representation of the RheoSwitch mammalian inducible expression system. RheoReceptor-1 (RR) and RheoActivator (RA) expressed from the pNEBR-R1 plasmid regulate transcription of mouse IER2 cloned into the pNEBR-X1 vector. b Western blot analysis of IER2 and vinculin (loading control) in three separate clones of NIH/3T3 mouse fibroblasts (3T3ind-IER2 \#11, \#19, and \#22), treated with DMSO or $0.2 \mu \mathrm{M}$ RSL. c Western blot analysis of IER2 and vinculin in 3 T3-ind-IER2 \#11 cells treated with $0.2 \mu \mathrm{M}$ RSL at the indicated time points. d Representative phase-contrast microscopic images (upper panel) and staining for SA$\beta$-galactosidase (SA- $\beta$-gal) activity (blue, lower panel) of 3T3-ind-IER2 \#11 cells treated for 3 days with DMSO or RSL (3 $\times 0.5 \mu$ M). Scale bars, $100 \mu \mathrm{m}$. e Percentage of SA- $\beta$-gal-positive 3T3-ind-IER2 \#11, \#19, and \#22 cells treated either with DMSO or RSL ( $3 \times 0.5 \mu \mathrm{M}$ ). Bars represent mean + SEM. More than 1000 cells per condition from 11 to 15 microscopic images were analyzed. $\mathbf{f}$ Cell cycle distribution of 3T3-ind-IER2 \#11 cells measured by flow cytometry after treatment with DMSO or RSL $(3 \times 0.5 \mu \mathrm{M})$. Bars represent mean + SEM $(n=3 ; 30,000$ cells per replicate were analyzed). $\mathbf{g}, \mathbf{h}$ GSEA enrichment plots and corresponding heat maps of selected differentially expressed genes belonging to the "p53 signaling pathway" (using KEGG annotations, g) or "Inflammatory response" (using GOBP annotations, h) associated with elevated IER2 expression. The red and blue colors in the bar-code plot indicate over- and under-expression in the mRNA. NES normalized enrichment score. i Western blot analysis of IER2, p53, p21, and vinculin in 3T3-ind-IER2 \#11 cells treated with either DMSO or RSL ( $3 \times 0.5 \mu M)$. Bars represent vinculin-normalized background-corrected integrated signal densities + SEM from three biological replicates. Data are normalized to DMSO-treated cells. Statistical significance was determined by an unpaired Student's $t$ test. ${ }^{*} p<0.05,{ }^{* *} p<0.01,{ }^{* * *} p<0.001$.

upon IER2 induction (Fig. 2f), consistent with cell cycle arrest. Unchanged $\mathrm{Rb}$ (retinoblastoma) phosphorylation and protein levels, together with unaffected $\mathrm{p} 16^{\mathrm{INK} 4 \mathrm{a}}$ (p16) levels indicate that IER2-mediated senescence is independent of the tumor-suppressor p16-Rb pathway [49] (Fig. S2i). RSL alone had no effect on cellular morphology, nor on the activation of the p53-p21 axis in control B16 cells, which were stably transfected with pNEBR-R1 plasmid alone (B16-R1; Figs. 2f and S2j). IER2 also had no impact on p53 mRNA levels, suggesting that IER2 regulates p53 posttranscriptionally (Fig. S3a, b). Consistently, p53 inhibition with pifithrin-a (PFT-a, Fig. 2g-i), as well as siRNA-mediated silencing of p53 (Fig. S2m, n) abrogated IER2-induced senescence, whereas stabilization of $\mathrm{p} 53$ by the MDM2 inhibitor nutlin-3 (NU-3) elicited a senescent phenotype in both B16 and Ret cells (Fig. 2g-i).

Next, we investigated whether IER2 is involved in $\mathrm{p} 53$ regulation following genotoxic stress. B16 cells were treated with the chemotherapy drugs doxorubicin and camptothecin with and without induction of IER2 expression. Elevated IER2 levels promoted earlier stabilization and activation of $\mathrm{p} 53$, as well as an earlier increase in p21 levels in response to both chemotherapeutics (Fig. S2k, I).

Together these data demonstrate that IER2 contributes to p53 regulation under both normal and stress conditions and that $\mathrm{p} 53$ is required for IER2-induced senescence. IER2 requires active AKT and MAPK signaling to promote p53-
dependent senescence in mouse melanoma cells

The RAS-RAF-MEK-ERK (MAPK) and PI3K-AKT (AKT) signaling pathways are key players in melanoma progression [50]. Oncogenic mutations that hyperactivate ERK and AKT can promote p53-dependent oncogene-induced senescence in a cell context-dependent manner $[49,51]$. Western blot analysis revealed rapid activation of both the MAPK and AKT pathways in response to IER2, as indicated by elevated phosphorylation of ERK1/2 at threonine 202 and tyrosine 204, and AKT at serine 473 and tyrosine 308 (Fig. 3a). These results suggest that IER2 may induce senescence via these pathways.

To investigate a possible role for the MAPK and AKT pathways in IER2-induced senescence, we inhibited the MAPK (MEKi) and AKT (AKTi) pathways alone and/or in combination in melanoma cells induced to express IER2, and compared p53 and p21 levels. MEK inhibition modestly decreased p53/p21 levels compared to untreated RSL-stimulated cells, while AKT inhibition completely abrogated IER2-induced p53 stabilization and substantially reduced p21 levels (Fig. 3b). Furthermore, both AKT and MEK inhibition abrogated the IER2-induced activation of mTOR (Fig. $3 b)$, which is involved in the induction of senescence via p53 $[51,52]$. Consistently, cells expressing IER2 showed a significant decrease in polyploidy (Figs. 3c, S3c, d) as well as in SA$\beta$-galactosidase activity in the presence of MEKi and/or AKTi (Fig. S3e, Fig. 3d).
These results reveal that MAPK and AKT signaling is mechanistically linked to IER2-induced senescence in melanoma.

\section{Osteopontin is a major component of the IER2-induced SASP} One of the hallmarks of senescence is the SASP $[28,53]$. SASP factors can promote inflammation and support tumor cell invasion and metastasis $[21,54,55]$. We, therefore, reasoned that IER2 could conceivably promote melanoma progression through the induction of senescence and specific SASP components. To identify the components of the IER2-induced SASP in B16 cells, we initially employed a small-scale qRT-PCR screen of common SASP signaling factors. Although the expression of the core SASP cytokines IL- 6 and CXCL15 (mouse homolog of IL-8 [56]) was markedly upregulated, the expression of other SASP-associated factors tested including IL-1a, IL-1 $\beta$, MMP3, CCL2, CXCL1, CXCL2, and CXCL5 was unaffected (data not shown). To identify other components of the IER2-induced SASP, we next employed a broader panel of 84 key genes involved in cancer inflammation and immunity (Fig. 4a, Table S3). The expression of 20 of these genes was significantly changed in response to IER2 expression, including genes previously identified in the transcriptomic analysis of IER2-expressing 3T3 cells (e.g., MYD88, TLR2, TLR3, TLR4, and IL23a). Figure $4 \mathrm{~b}$ summarizes genes that encode secreted proteins whose expression was increased more than twofold upon induction of IER2 expression. These data were validated by qRTPCR (Fig. 4c), and also at the protein level for OPN (Fig. S4a). Together, these data suggest that the IER2-dependent SASP in B16 melanoma cells includes OPN, CXCL15, CCL5, IL-6, and IL-23a.

As OPN was by far the most highly upregulated gene in response to IER2 expression (Fig. 4a), and is known to play an important role in tumorigenesis and metastasis [57, 58], subsequent work focused on this gene. To explore the role of p53 in IER2-induced OPN expression, we treated IER2-inducible B16 and Ret cells with PFT- $a$ and NU-3 and monitored OPN expression and secretion. Inhibition of p53 with PFT-a strongly suppressed the ability of IER2 to induce OPN transcription, while stabilization of p53 with NU-3 had no significant effect (Ret cells) or even enhanced OPN expression (B16 cells) (Fig. 4d). Similarly, the massive IER2-induced secretion of OPN (sOPN, secreted osteopontin) was strongly attenuated by inhibition of p53 with PFT-a, while it was maintained when cells were treated with NU-3 (Fig. $4 \mathrm{e}$, for anti-OPN antibody specificity, see Fig. S4a).

To validate these findings in human melanoma cells, we ectopically expressed IER2 in p53 ${ }^{\text {wt }}$ A375 cells, and in SK-Mel-28 cells, which carry a homozygous loss-of-function mutation in p53 $\left(\mathrm{p} 53^{\mathrm{L} 145 \mathrm{R}}\right)$ and therefore have only very low levels of $\mathrm{p} 21$ expression [59-61]. OPN expression and secretion, as well as the percentage of senescent cells, were significantly increased by ectopic expression of IER2 in p53 ${ }^{\text {wt }}$ A375 cells, but not in p53 ${ }^{\mathrm{L} 145 \mathrm{R}}$ SK-Mel-28 cells (Fig. S4b-d). In addition, the senescence phenotype in A375 cells was accompanied by activation of the AKT 
a



d



g
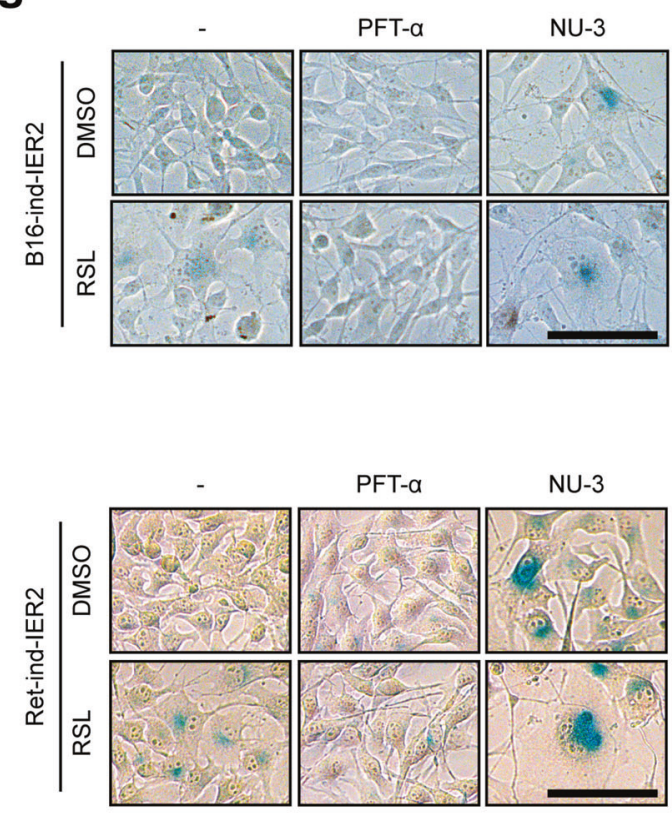

C

DMSO

$+\quad$ RSL

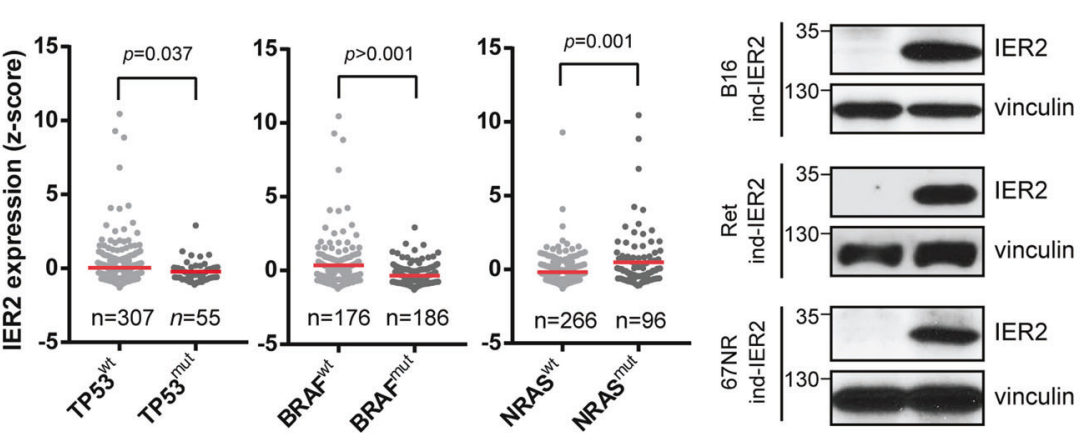

e

f



h

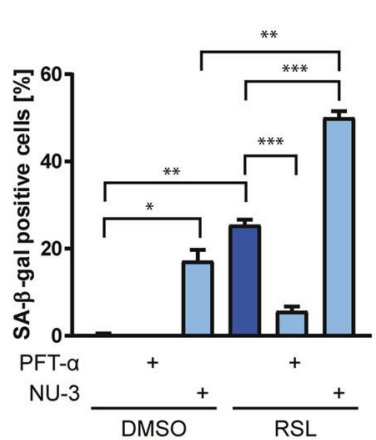

|
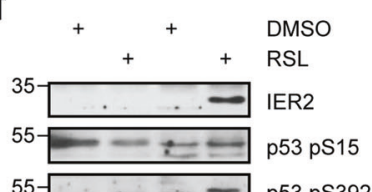

$55-$ p53 ps392

$55--\ldots$ p53

$25 \square$ p21

$25 \div$ p27

vinculin

$100 \ldots$ MDM2-FL

D5 - - MDM2-iso

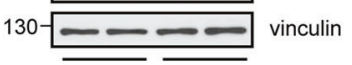
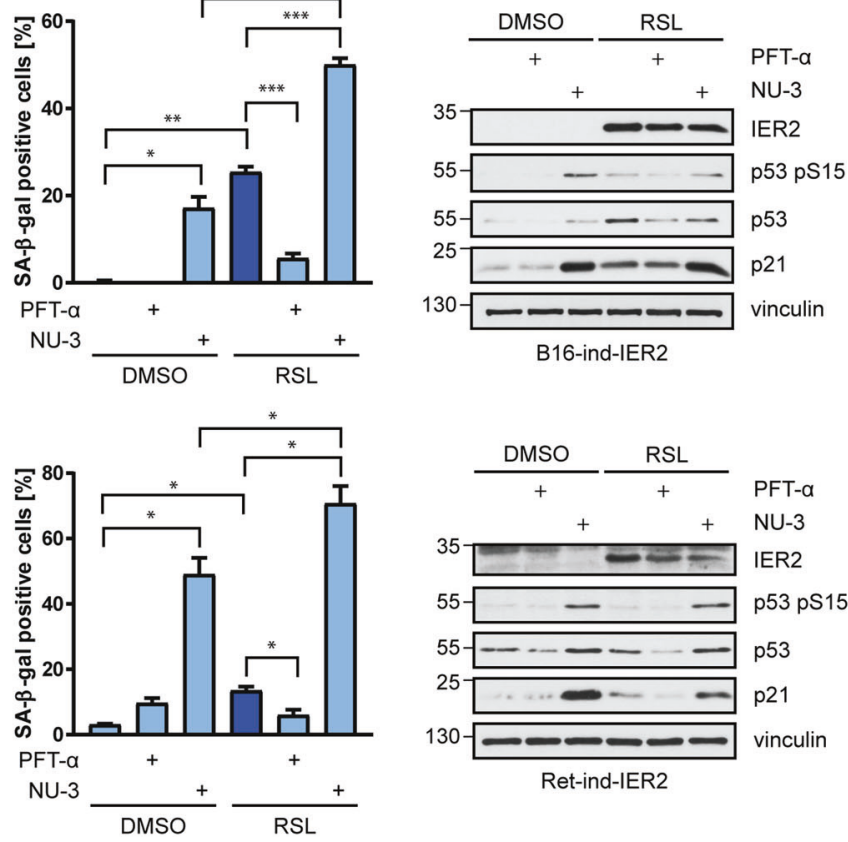

kinase and p53/p21 pathways, consistent with the results obtained in murine melanoma cells (Fig. 4e).

Since active ERK and AKT are important for IER2-induced p53 stabilization and senescence (Fig. 3b-e), we next examined whether inhibition of both pathways alone or in combination affects levels of the OPN protein. In contrast to the MEK inhibition,

AKT inhibition resulted in a substantial decrease in secreted OPN upon IER2 expression both in B16 and Ret cells (Fig. 4f).

Together, these data indicate that sustained expression of IER2 can lead to a characteristic secretory phenotype in melanoma cells, a major component of which is OPN, which is upregulated in an AKT/p53-dependent manner. 
Fig. 2 IER2 requires p53-p21 to promote senescence in murine melanoma cells. a Kaplan-Meier analysis of the overall survival of the TCGA skin cutaneous melanoma cohort $(n=471)$ stratified according to low (IER2 ${ }^{\text {low }}$ ) and high (IER2 $\left.{ }^{\text {high }}\right)$ IER2 expression. b IER2 expression in the skin cutaneous melanoma cohort from (a), with patients stratified according to p53 (left), BRAF (middle) and NRAS (right) mutational status. The red lines represent the means. c Western blot analysis of IER2 and vinculin (loading control) in B16-ind-IER2 \#51, Ret-ind-IER2 \#69, and $67 N R$-ind-IER2 \#37 RheoSwitch cells treated either with DMSO or RSL $(3 \times 0.5-1.0 \mu \mathrm{M})$. d Staining for SA- $\beta$-galactosidase activity (blue) in B16ind-IER2 \#51 and 67NR-ind-IER2 \#37 cells treated either with DMSO or with RSL $(3 \times 0.5 \mu \mathrm{M})$. Scale bar, $100 \mu \mathrm{m}$; inset $25 \mu \mathrm{m}$. e Percentage of SA$\beta$-galactosidase-positive cells in B16-ind-IER2 \#51, Ret-ind-IER2 \#69, and 67NR-ind-IER2 \#37 cells after stimulation with DMSO or RSL (3× $0.5-1.0 \mu \mathrm{M} ; n=3)$. $\mathrm{f}$ Western blot analysis of the indicated proteins in parental B16-R1 \#2 and B16-ind-IER2 \#51 cells after stimulation with either DMSO or RSL $(3 \times 0.5 \mu \mathrm{M})$. g Representative images of staining for SA- $\beta$-galactosidase activity (blue) and $\mathbf{h}$ quantification of SA$\beta$-galactosidase staining in B16-ind-IER2 \#51 cells (upper panels) and Ret-ind-IER2 \#69 cells (bottom panels) treated with PFT- $\alpha$ (20 $\mu$ M) or NU-3 $(5 \mu \mathrm{M})$ with or without stimulation with RSL $(3 \times 0.5 \mu \mathrm{M}) ; n=3$. Scale bars, $100 \mu \mathrm{m}$. i Western blot analysis of IER2, p53 pS15, p53, and p21 in B16-ind-IER2 \#51 (upper panel) and Ret-ind-IER2 \#69 cells (bottom panel) treated as in g. Bars represent mean + SEM; $n=3$. Statistical significance was determined using an unpaired Student's $t$ test. n.s. nonsignificant $(p>0.05),{ }^{*} p<0.05,{ }^{* *} p<0.01,{ }^{* * *} p<0.001$.
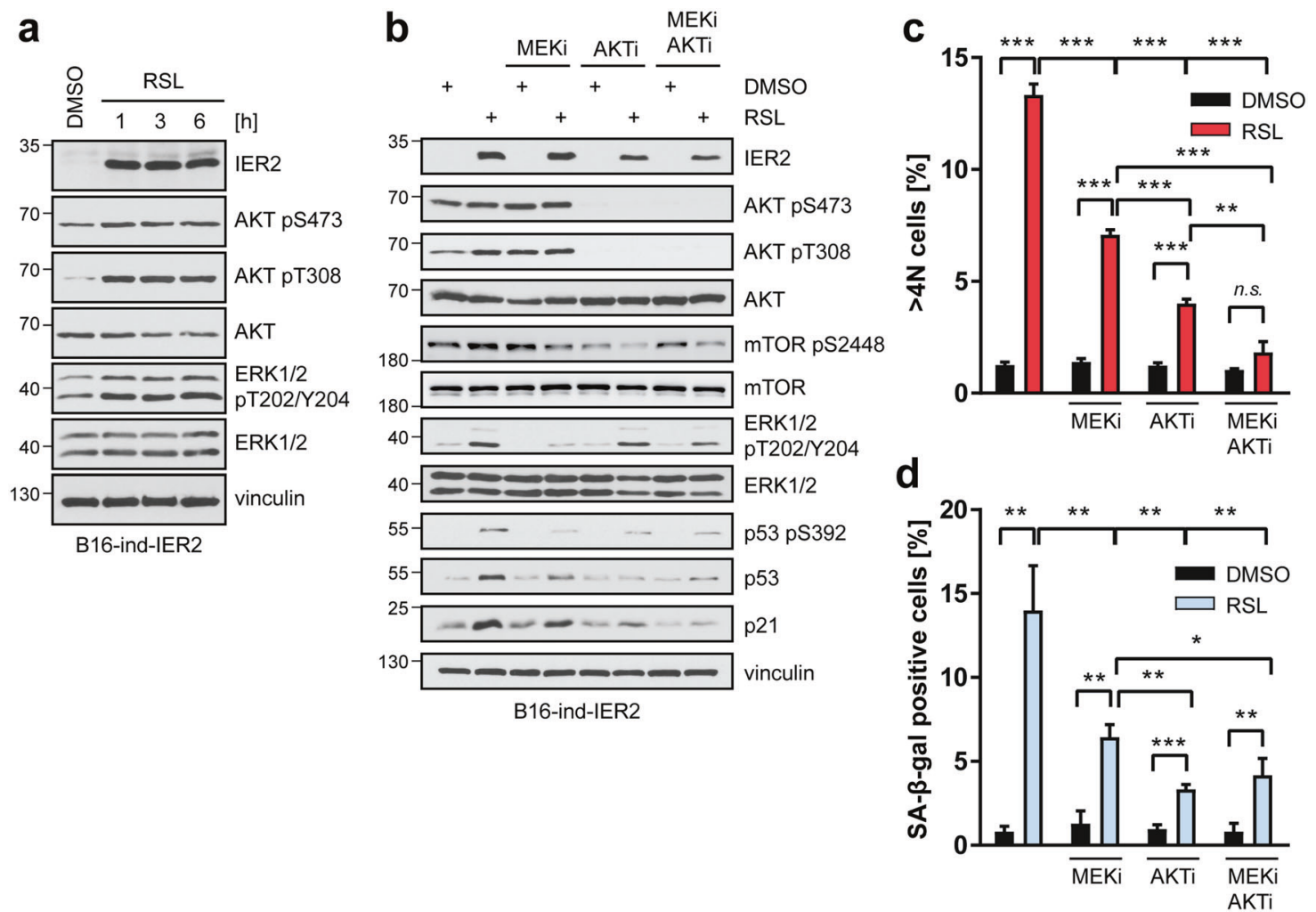

Fig. 3 IER2 requires active AKT and ERK signaling to promote p53-dependent senescence in melanoma cells. a Western blot analysis of IER2, AKT phosphorylated on serine 473 (pS473) and threonine 308 (pT308), AKT, ERK phosphorylated on threonine 202/tyrosine 204 (pT202/ Y204), ERK1/2, and vinculin (loading control) in B16-ind-IER2 \#51 cells treated with DMSO or RSL $(3 \times 0.5 \mu \mathrm{M})$, harvested at indicated time points after the last dose of RSL. b Western blot analysis of the indicated proteins in B16-ind-IER2 \#51 cells treated with MEKi $(3 \times 1 \mu \mathrm{M})$ and/or $\operatorname{AKTi}(3 \times 1 \mu \mathrm{M})$, with or without stimulation with RSL $(3 \times 0.5 \mu \mathrm{M})$. c DRAQ5 labeling of nuclear DNA followed by flow cytometry quantification of $>4 \mathrm{~N}$ B16-ind-IER2 \#51 cells treated either with DMSO or with RSL $(3 \times 0.5 \mu \mathrm{M})$ in combination with MEKi $(3 \times 1 \mu \mathrm{M})$ and/or AKTi $(3 \times 1 \mu \mathrm{M})$. d Percentage of SA- $\beta$-galactosidase-positive B16-ind-IER2 \#51 cells treated as in (c). Bars represent means + SEM; $n=3$. Statistical significance was determined using an unpaired Student's $t$ test. n.s. nonsignificant $(p>0.05),{ }^{*} p<0.05,{ }^{* *} p<0.01,{ }^{* * *} p<0.001$.

\section{IER2-driven OPN is expressed by senescent cells}

The above results suggest that IER2 induces senescence stochastically, as senescence was only observed in around $10-25 \%$ of the cells (Figs. 2d, e, S4d). Therefore, we next assessed whether OPN is secreted by non-senescent $(\mathrm{N})$ or senescent $(\mathrm{S})$ cells after IER2 induction. We took advantage of the increased cellular size of senescent cells to sort them by flow cytometry-based on forward and side scatter (Fig. S5a, b). In line with previous results, IER2 induction markedly increased the percentage of enlarged senescent melanoma cells in the flow cytometry (Fig. S5b). The enrichment of senescent cells in the sorted fraction was confirmed by re-evaluation post-sorting (Fig. 5a), by monitoring of cellular morphology and SA- $\beta$-galactosidase activity (Fig. 5 b), as well as by cell cycle analysis, including analysis of the percentage of $>4 \mathrm{~N}$ cells (Figs. S5c, 5c). The senescence-enriched fraction also exhibited higher MDM2-iso and p21 levels compared to the non-senescent fraction (Fig. 5e), reflecting p53 activation. Although IER2 levels were elevated to the same extent in senescent and non-senescent cells, OPN was predominantly expressed by the senescent cellenriched population (Fig. 5d, e). Notably, in contrast to the nonsenescent fraction that showed higher levels of activated ERK1/2, the senescence-enriched fraction exhibited enhanced AKT activation (Fig. 5e). This is consistent with our observation that OPN secretion is abrogated by AKT inhibition but not ERK inhibition (Fig. $4 f)$. Together, these data indicate that (i) the stochastic induction of senescence and OPN expression in response to IER2 is not due to variation in the expression level of IER2 within distinct subpopulations of cells, (ii) that enhanced IER2 expression does not induce senescence and OPN expression in all cells, and (iii) that OPN is part of the IER2-induced AKT/p53-dependent SASP. 
a
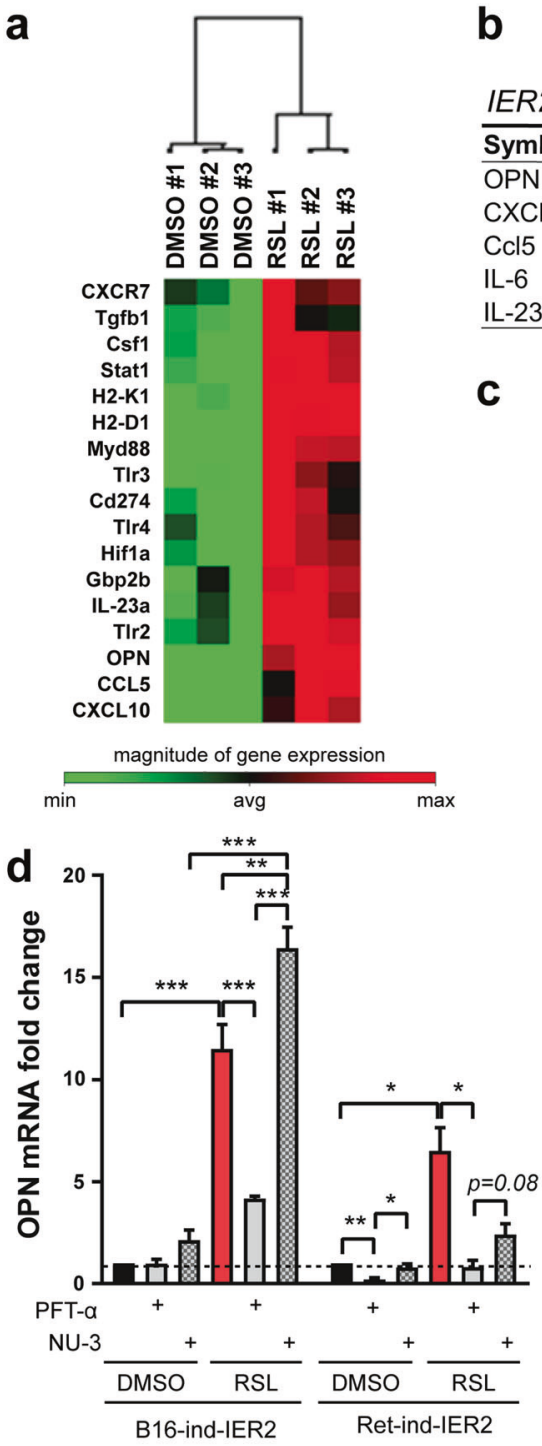

b

C
IER2-induced secreted factors

\begin{tabular}{llll}
\hline Symbol & Description & FC & p-value \\
\hline OPN & Osteopontin & 22.36 & 0.00030 \\
CXCL15 (IL-8) & Chemokine (C-X-C motif) ligand 15 & 17.65 & 0.00750 \\
CCl5 & Chemokine (C-C motif) ligand 5 & 4.90 & 0.00673 \\
IL-6 & Interleukin 6 & 4.46 & 0.04738 \\
IL-23a & Interleukin 23, alpha subunit p19 & 2.32 & 0.00986 \\
\hline
\end{tabular}

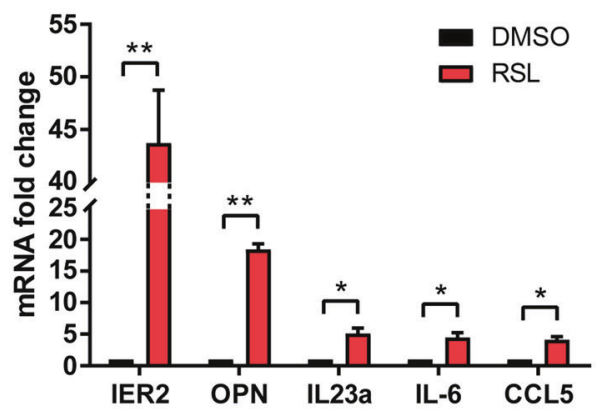

e



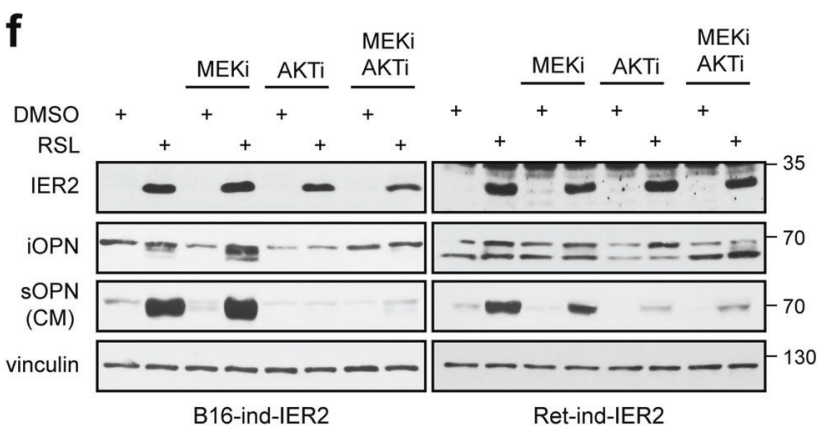

Fig. 4 Osteopontin is a major component of the p53-dependent IER2-induced SASP. a Heatmap showing the top IER2-induced genes in B16-ind-IER2 \#51 cells treated either with DMSO or RSL $(3 \times 0.5 \mu \mathrm{M})$ assessed using a Mouse Cancer Inflammation and Immunity Crosstalk PCR Array. b IER2-induced genes based on the qRT-PCR analysis (CXCL15, IL-6) and the Mouse Cancer Inflammation and Immunity Crosstalk PCR Array (OPN, Ccl5, and IL23a). Only genes with a fold change (FC) $\geq 2.0$ and $p<0.05$ are shown. See also Table S3. c qRT-PCR quantification of IER2, OPN, IL-23a, IL-6, and CCL5 in B16-ind-IER2 \#51 cells treated with either DMSO or RSL $(3 \times 0.5 \mu M)$. RPLP0 was used for normalization. Bars represent means + SEM; $n=3$. d qRT-PCR quantification of OPN in B16-ind-IER2 \#51 and Ret-ind-IER2 \#69 cells treated with PFT- $\alpha$ ( $20 \mu M$ ) or NU-3 $(5 \mu \mathrm{M})$ with or without stimulation with RSL $(3 \times 0.5$ and $1 \mu \mathrm{M})$. RPLP0 was used for normalization in qRT-PCR. Bars represent mean + $\mathrm{SEM} ; n=3$. e Western blot analysis of intracellular OPN (iOPN), IER2, p53, p21, vinculin (loading control), and secreted OPN (sOPN) present in conditioned media (CM) of B16-ind-IER2 \#51 and Ret-ind-IER2 \#69 cells treated with PFT- $\alpha(20 \mu \mathrm{M})$ or NU-3 $(5 \mu \mathrm{M})$, with or without stimulation with RSL $(3 \times 0.5$ and $1 \mu \mathrm{M})$. f Western blot analysis of intracellular OPN (iOPN), IER2, vinculin, and secreted OPN (sOPN) present in conditioned media (CM) of B16-ind-IER2 \#51 and Ret-ind-IER2 \#69 cells treated with or without RSL $(3 \times 0.5$ and $0.5 \mu \mathrm{M})$ in the presence or absence of MEKi and/or AKTi (both $3 \times 1 \mu \mathrm{M}$ ). Statistical significance was determined using an unpaired Student's $t$ test. ${ }^{*} p<0.05,{ }^{* *} p<0.01$. 
a $\square$ non-senescent cells $\square$ senescent cells



C

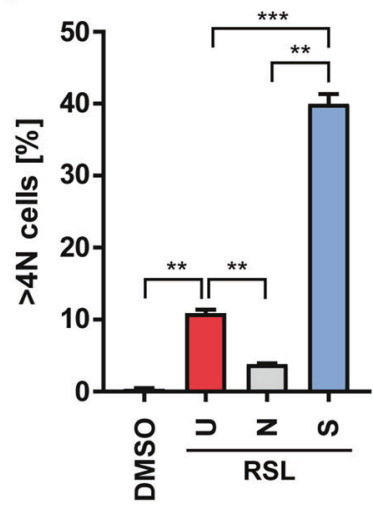

f



b



d

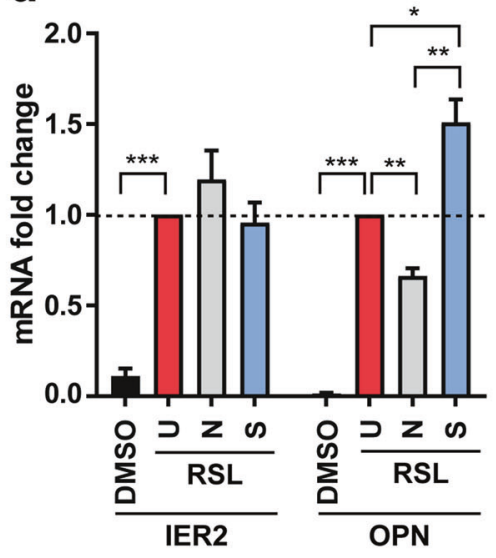

g

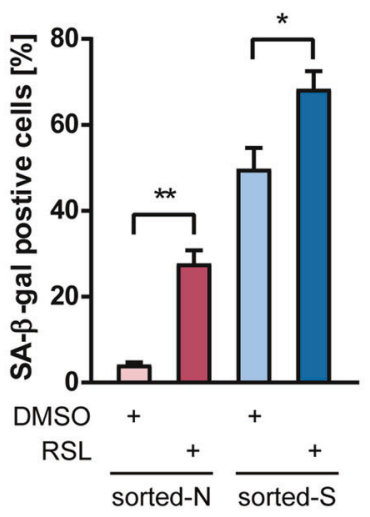

e



Fig. 5 IER2 only induces osteopontin expression in senescent cells. a B16-ind-IER2 \#51 cells were sorted into non-senescent (N) or senescent (S) cells, and enrichment of the corresponding types of cells in the sorted fractions was controlled by immediate post-sorting flow cytometry analysis. Bars represent means + SEM from three independent sorts. b Representative images showing cellular morphology and SA- $\beta$-galactosidase (SA- $\beta$-gal) activity (blue) in RSL-treated $(3 \times 0.5 \mu \mathrm{M})$ unsorted (U), sorted non-senescent (N) and sorted senescent $(\mathrm{S})$ B16ind-IER2 \#51 cells. DMSO-treated cells were used as a control. Scale bar, $100 \mu \mathrm{m}$. c DRAQ5 labeling of nuclear DNA followed by flow cytometry quantification of $>4 \mathrm{~N}$ B16-ind-IER2 \#51 cells treated and sorted as in (b). See also Fig. S5c for the complete cell cycle profile. Bars represent mean + SEM, $n=3$. d, e qRT-PCR quantification of IER2 and OPN (d) and Western blot analysis (e) of the indicated proteins in RSL-treated ( $3 \times$ $0.5 \mu \mathrm{M})$ unsorted $(\mathrm{U})$, sorted non-senescent $(\mathrm{N})$ and sorted senescent $(\mathrm{S})$ B16-ind-IER2 \#51 cells. RPLP0 was used for normalization. DMSOtreated cells were used as a control. Bars in (e) represent mean + SEM; $n=5$. f Schematic depiction of the sorting strategy for B16-indIER2\#51 cells treated before and after sorting either with DMSO or RSL $(3 \times 0.5 \mu \mathrm{M})$. g B16-ind-IER2 \#51 cells were treated for 3 days $(3 \times 0.5 \mu \mathrm{M})$ with RSL and sorted into non-senescent and senescent populations, each of which was subsequently treated for 3 days with DMSO or RSL $(3 \times 0.5 \mu \mathrm{M})$, followed by SA- $\beta$-gal staining. Bars represent mean $+\mathrm{SEM} ; n=4$. Statistical significance was determined using an unpaired Student's $t$ test. ${ }^{*} p<0.05,{ }^{* *} p<0.01,{ }^{* * *} p<0.001$. 

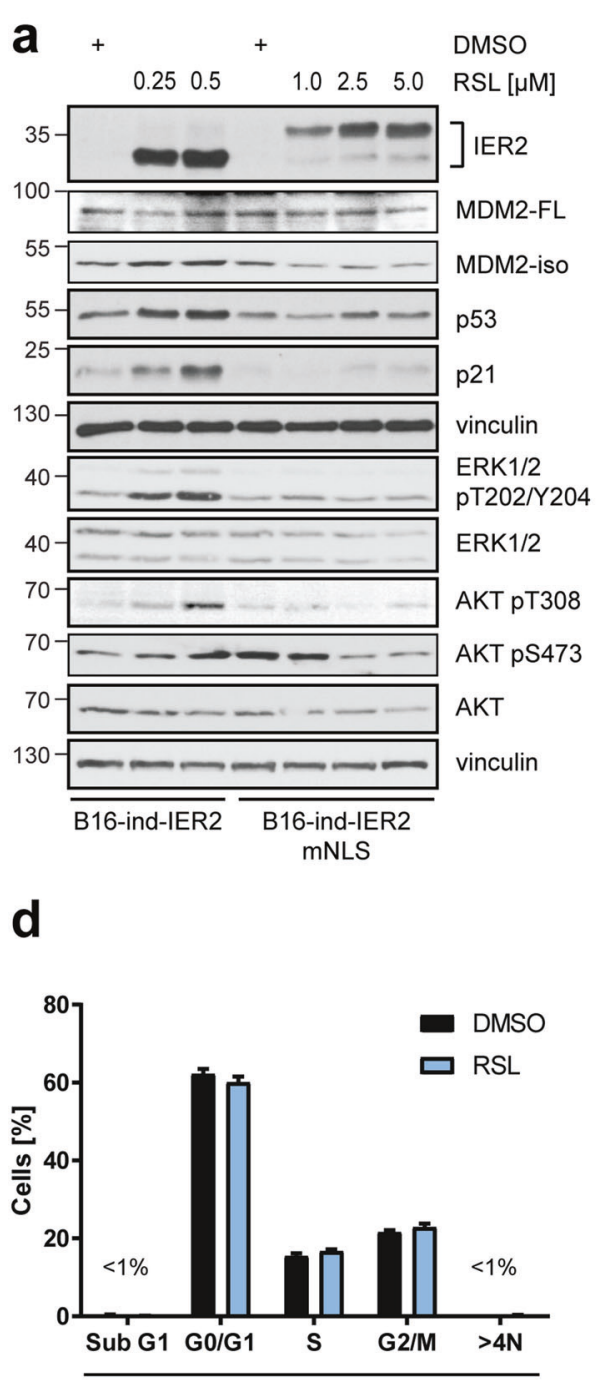

B16-ind-IER2-mNLS b

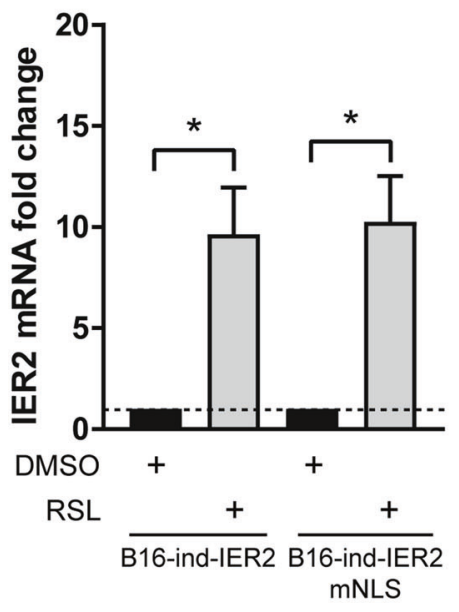

e

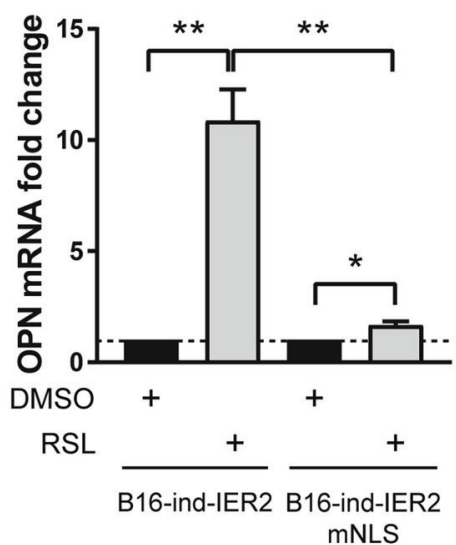

C



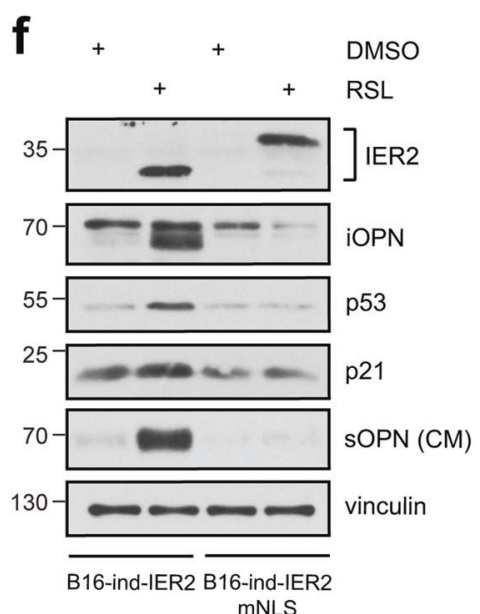

mNLS

Fig. 6 Nuclear localization of IER2 is required for senescence induction and osteopontin secretion. a Western blot analysis of the indicated proteins in B16-ind-IER2 \#51 and B16-ind-IER2-mNLS \#56 cells, treated with RSL at the indicated concentrations. DMSO was used as a control. b qRT-PCR quantification of IER2 in B16-ind-IER2 \#51 (treated with DMSO or $0.25 \mu M$ RSL) and B16-ind-IER2-mNLS \#56 cells (treated with DMSO or $5 \mu \mathrm{M}$ RSL). RPLP0 was used for normalization. Bars represent mean $+\mathrm{SEM} ; n=4$. c Quantification of SA- $\beta$-galactosidase (SA- $\beta$-gal)-positive B16-ind-IER2 \#51 cells (treated with DMSO or $3 \times 0.25 \mu \mathrm{M} \mathrm{RSL}$ ) and B16-ind-IER2-mNLS \#56 cells (treated with DMSO or $3 \times 5 \mu \mathrm{M}$ RSL). Bars represent mean $+\mathrm{SEM} ; n=3$. d DRAQ5 labeling of nuclear DNA followed by flow cytometry-based cell cycle analysis of B16-ind-IER2-mNLS \#56 cells after treatment with DMSO or RSL $(3 \times 5 \mu \mathrm{M})$. Bars represent mean $+\mathrm{SEM} ; n=3 ; 30,000$ cells were analyzed per replicate. e, $\mathbf{f}$ qRT-PCR quantification of OPN (e) and Western blot analysis (f) of IER2, intracellular OPN (iOPN), p53, p21, vinculin, and secreted OPN (sOPN) in conditioned medium (CM) in B16-ind-IER2 \#51 (treated with DMSO or $3 \times 0.25 \mu \mathrm{M}$ RSL) and B16-ind-IER2-mNLS \#56 cells (treated with DMSO or $3 \times 5 \mu \mathrm{M} \mathrm{RSL}$ ). Bars represent mean $+\mathrm{SEM} ; n=4$. Statistical significance was determined using an unpaired Student's $t$ test. n.s. nonsignificant $(p>0.05),{ }^{*} p<0.05,{ }^{* *} p<0.01$.

To investigate whether the sorted non-senescent IER2-expressing B16 and Ret cells are resistant to IER2-induced senescence, they were exposed to an additional round of either DMSO or RSL treatment (Fig. 5f). IER2 induced senescence in these cells to the same extent $(\sim 25 \%)$ as in the non-sorted parental population (Fig. S5d, Fig. $5 \mathrm{~g}$ ). The sorted senescent cell-enriched fraction failed to revert to a non-senescent phenotype when IER2 expression was no longer maintained. Moreover, an additional round of RSL stimulation further increased the percentage of senescent cells in this fraction (Fig. S5d, Fig. 5g).

Overall, these data suggest that IER2 expression leads to stochastic senescence development in a fraction of melanoma cells, which elicits the production of OPN.
IER2 nuclear localization is critical for senescence development and OPN secretion

IER2 contains a putative bipartite NLS [9] that is conserved across species (Fig. S6a). To investigate whether the subcellular localization of IER2 is important for the induction of senescence and OPN secretion, we generated a RheoSwitch B16 cell line inducible for IER2 with a mutation in the first part of the putative NLS (IER2mNLS, Fig. S6b). To be able to determine the effect of wild-type IER2 (IER2-wt) vs. mutated IER2-mNLS, we first titrated the RSL concentration required to achieve comparable induction of IER2 in both cell lines (Fig. 6a). Unexpectedly, IER2-mNLS exhibited altered electrophoretic mobility in sodium dodecyl sulfate-polyacrylamide gel electrophoresis (SDS-PAGE), producing two immunoreactive 
bands, indicative of possible changes in posttranslational modifications as a result of altered structure or cellular localization. Equivalent IER2 expression was further confirmed by qRT-PCR (Fig. $6 b)$. Immunofluorescence staining of B16 cells expressing IER2-wt and IER2-mNLS confirmed that IER2-wt is partially localized in the nucleus, whereas IER2-mNLS is restricted to the cytoplasm (Fig. S6c).

In contrast to IER2-wt, IER2-mNLS induction failed to increase the levels of p53, MDM2-iso, and p21, or to activate the ERK and AKT kinases (Fig. 6a), and did not induce senescence (Fig. S6d, Fig. 6c) or result in alterations in the cell cycle (Fig. 6d). Furthermore, the nuclear localization of IER2 was crucial for the development of the IER2-induced SASP, as IER2-mNLS induced no, or only a much weaker upregulation of the IER2-wt-dependent SASP factors, including OPN (Figs. 6e, f, S6e).

Collectively, these data support the notion that the nuclear localization of IER2 is required for induction of senescence, as well as for production of the IER2-specific SASP that includes OPN.

\section{IER2 promotes melanoma migration and invasion via secreted} OPN

We have previously reported that IER2 is rapidly translocated to the nucleus of actively migrating pancreatic tumor cells after relief of contact inhibition [13]. Therefore, we next assessed whether the nuclear localization of IER2 impacts the migration of B16 cells. The proliferation of B16 cells expressing IER2-wt was lower than that of IER2-mNLS-expressing cells (Fig. S7a). However, the migration of cells expressing IER2-wt was enhanced in comparison to IER2mNLS-expressing cells (Fig. S7b). We also investigated whether the nuclear localization of IER2 promotes melanoma invasion. Again, expression of IER2-wt strongly promoted melanoma cell invasion, whereas expression of IER2-mNLS even suppressed invasion, rather than promoting it (Fig. 7a).

To dissect the role of OPN in IER2-mediated invasion, we generated IER2-inducible B16 cells with CRISPR/Cas9-mediated knockout of OPN (OPN-KO, Fig. 7b, Fig. S7f). These cells retained the ability to induce $\mathrm{p} 53$ and to develop a senescence phenotype upon IER2 induction (Figs. 7b, S7c, d). IER2 expression, as well as the absence of OPN, had no effect on proliferation in these cells (Fig. S7e). By contrast, deletion of OPN completely abrogated the ability of wild-type IER2 to promote melanoma cell invasion (Fig. 7a, S7f, g).

Senescent fibroblasts can stimulate the invasiveness of malignant epithelial cells via paracrine signaling [62]. Therefore, we next assessed whether conditioned medium (CM) from IER2-expressing B16 cells can affect the migration and invasion of parental, nonsenescent B16 cells. CM from IER2-wt-expressing cells robustly induced the migration and invasion of parental B16 cells (Fig. 7c, d). By contrast, CM from IER2-mNLS-expressing cells or from IER2wt-expressing cells with a knockout of OPN (OPN-KOs) had no impact on the migration and invasion of parental, non-senescent B16 cells (Fig. 7c, d). Interestingly, CM from IER2-wt-expressing B16 cells had no effect on the migration, invasion or soft agar growth of normal melanocytes (Fig. S8a-d), demonstrating that the IER2driven secretome is not sufficient to modify the transformation status or invasive behavior of non-malignant melanocytes.

Together, these results demonstrate that IER2 fosters melanoma cell migration and invasion in a manner that requires nuclear localization of the IER2 protein. IER2-induced OPN expression mediates these effects and can act in a paracrine manner on neighboring, non-senescent cancer cells.

\section{IER2 levels correlate with OPN expression in human melanoma}

To gain insight into the association between the IER2-p53 axis and OPN expression in human melanoma, we first performed immunohistochemistry analysis of IER2 and OPN expression in tissue biopsies from patients with primary melanomas. Immuno- staining of serial sections revealed co-expression of IER2 and OPN in melanoma nests (Fig. 8a). To investigate the relationship between IER2 and OPN expression during melanoma progression, we analyzed tissue microarrays (TMAs) containing human melanocytic nevi (MN), primary melanomas (primary tumors, PT), and distant melanoma metastasis (DM). Expression intensity and abundance were assessed in a blinded fashion by two independent researchers using a defined immunohistochemical score for each probe (Fig. S9a). This analysis demonstrated a significant upregulation of both IER2 and OPN protein expression in primary melanomas, compared to MN, and further upregulation of OPN in distant metastases (Fig. 8b, for clinicopathological data, see Table S4). These observations are consistent with previous reports showing that OPN expression correlates with melanoma invasion [63]. Furthermore, our TMA analysis revealed a significant correlation between IER2 and OPN protein expression in MN, PT, and distant metastases (Fig. 8c, for clinicopathological data, see Table S4).

We next aimed to determine whether IER2 and OPN expression is linked to a p53/p21-driven senescence-like state in melanomas, as suggested by our results using melanoma cell lines. Since the paraffin embedding used for the TMA samples destroys $\beta$-galactosidase activity, we used p53 status combined with p21 expression ( $\mathrm{p} 53^{\text {pos }} / \mathrm{p} 21^{\text {high }}$ versus $\mathrm{p} 53^{\text {neg }} / \mathrm{p} 21^{\text {low }}$, see Fig. S9b, c for IHC staining) as a surrogate marker of senescent cells. Importantly, both IER2 and OPN showed significantly higher expression in patients with an active p53-p21 pathway ( $\left.553^{\text {pos }} / \mathrm{p} 21^{\text {high }}\right)$, consistent with our findings that demonstrate a functional link between IER2, p53, and OPN (Fig. 8d, for clinicopathological information, see Table S5).

Taken together, these data provide evidence that the p53dependent IER2-induced senescence and OPN expression, we observed in cultured melanoma cells, reflects the situation in human melanoma.

\section{DISCUSSION}

Here, we report that high levels of IER2 in human melanoma samples correlate with increased p53/p21 and OPN levels, as well as with poor patient prognosis. Mechanistically, we show that IER2 upregulates p53 protein expression via increased expression of MDM2-iso and enhanced activation of AKT and ERK1/2, which leads to the stochastic induction of senescence in melanoma cells. The senescent cells express a characteristic SASP, a major component of which is OPN. OPN from the senescent cells acts in a paracrine manner to promote motility and invasion of nonsenescent melanoma cells (Fig. 8e).

Our data suggest that constitutive expression of IER2 on the one hand leads to accumulation of MDM2-iso, and on the other to increased activation of AKT and ERK1/2, all of which leads to stabilization of p53 and expression of p21 (Fig. 8e). These data are consistent with the induction of premature senescence that is observed in response to constitutive MEK/MAPK signaling [64], and with the DNA damage-independent increase in p53 levels and senescence that are induced via mTORC1 in response to PI3K/AKT pathway activation [51]. Activation of AKT, which can be promoted by IER2 [17], also increases intracellular ROS levels by inducing oxygen consumption or by inhibiting the forkhead box $\mathrm{O}$ (FOXO) family of transcription factors, which further fosters cellular senescence $[65,66]$.

Our data indicate that OPN is a major component of the IER2induced SASP in melanoma. OPN has previously been identified in some but not all SASPs in a context-dependent manner. OPN is a component of the bleomycin-induced senescence SASP that is produced independently of DNA damage, and can also be produced by senescent stromal cells within the tumor microenvironment $[67,68]$. OPN is additionally produced by senescent pulmonary artery smooth muscle cells and contributes to the 

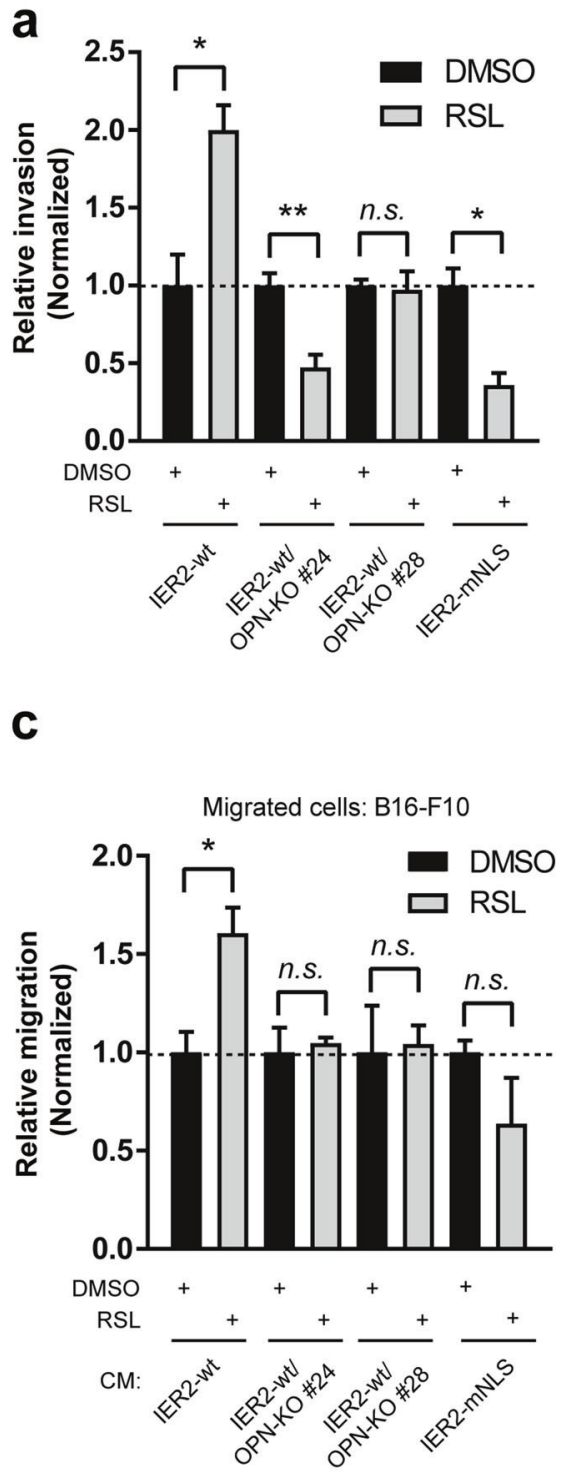

b
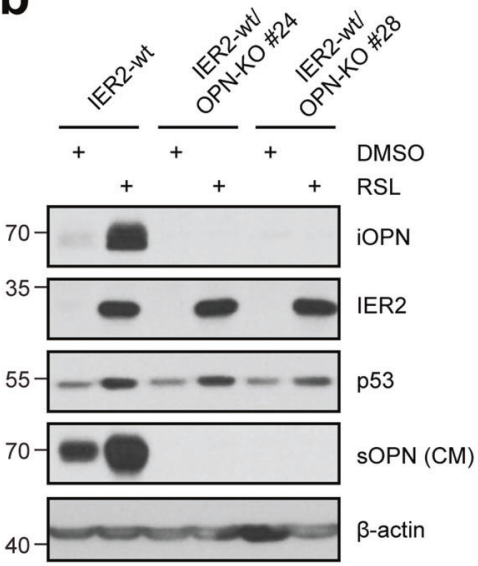

C

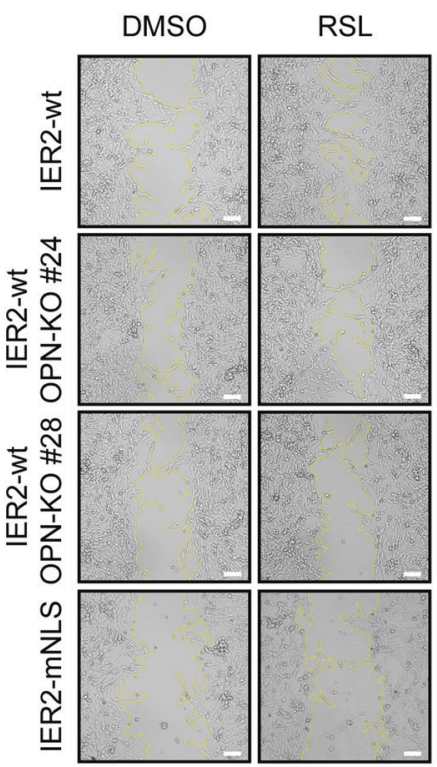

d

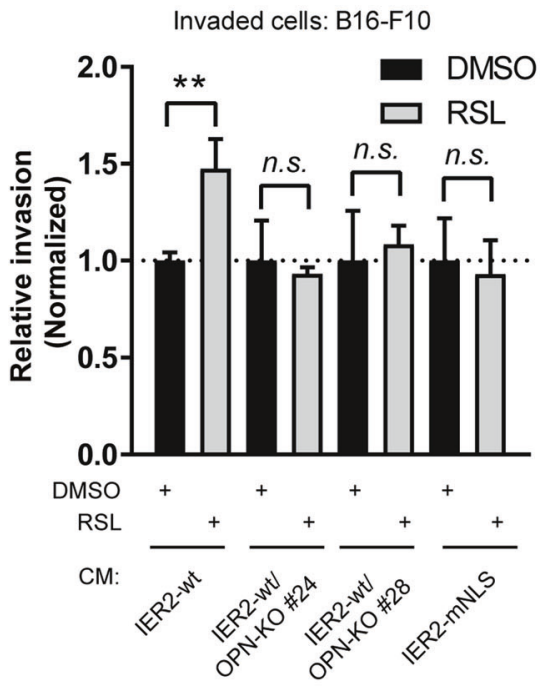

Fig. 7 IER2 promotes melanoma cell migration and invasion in vitro in an osteopontin-dependent manner. a Invasion of B16-ind-IER2 \#51, B16-ind-IER2-OPN-KO \#24, B16-ind-IER2-OPN-KO \#28, and B16-ind-IER2-mNLS \#56 (IER2-mNLS) cells seeded in DMEM/1\% FBS and treated either with DMSO or RSL $(5 \times 0.5 \mu \mathrm{M}$ in the case of IER2-wt or $30 \mu \mathrm{M}$ in the case of IER2-mNLS cells). Data represent relative invasion through a Matrigel layer $(0.8 \mathrm{mg} / \mathrm{ml})$ towards DMEM $/ 10 \% \mathrm{FBS}$ at $64 \mathrm{~h}$ and are shown as mean $+\mathrm{SEM} ; n=3$. Data are normalized to DMSO-treated controls. b Western blot analysis of intracellular OPN (iOPN), IER2, p53, $\beta$-actin (loading control), and secreted OPN (sOPN) in conditioned medium (CM) in B16-ind-IER2 \#51 (IER2-wt) cells, as well as in B16-ind-IER2-OPN-KO \#24 (IER2-wt/OPN-KO \#24) and B16-ind-IER2-OPN-KO \#28 (IER2-wt/OPN-KO \#28) cells, in which osteopontin was deleted through CRISPR/Cas9-mediated gene inactivation, treated either with DMSO or RSL $(3 \times 0.5 \mu \mathrm{M})$. c Migration of wild-type B16-F10 cells $32 \mathrm{~h}$ after removal of silicone inserts in the presence of CM from B16-ind-IER2 \#51, B16ind-IER2-OPN-KO \#24, B16-ind-IER2-OPN-KO \#28, and B16-ind-IER2-mNLS \#56 cells treated either with DMSO or RSL $(3 \times 0.5 \mu M$ in case of IER2wt or $30 \mu \mathrm{M}$ in case of IER2-mNLS cells). Data represent relative migration + SEM from 3 to 4 biological replicates normalized to DMSO-treated controls. Scale bar, $100 \mu \mathrm{m}$. d Invasion of wild-type B16-F10 cells in the presence of CM from B16-ind-IER2 \#51, B16-ind-IER2-OPN-KO \#24, B16ind-IER2-OPN-KO \#28, and B16-ind-IER2-mNLS \#56 cells that were seeded in DMEM/1\% FBS and treated either with DMSO or RSL $(5 \times 0.5 \mu M$ in the case of IER2-wt or $30 \mu \mathrm{M}$ in the case of IER2-mNLS cells). Data represent relative invasion through a Matrigel layer (0.8 mg/ml) toward $\mathrm{DMEM} / 10 \% \mathrm{FBS}$ at $48 \mathrm{~h}$ and are shown as mean $+\mathrm{SEM} ; n=3$. Data are normalized to DMSO-treated controls. n.s. nonsignificant ( $p>0.05)$, ${ }^{*} p<0.05,{ }^{*} p<0.01$, with significance determined by an unpaired Student's $t$ test.

progression of pulmonary hypertension [69]. Context-dependent inclusion of OPN in the SASP presumably reflects the fact that multiple signaling pathways regulate the SASP, including the DDR, p38 MAP kinase, and cGAS/STING pathways [70]. Our data indicate that AKT plays an important role in regulating the IER2-induced SASP that includes OPN, which is consistent with the observation that the downstream AKT target mTOR controls the senescent secretome through regulating the stability of SASP mRNAs [71]. In bleomycin-induced senescence, the transcription factors c-Myb and $\mathrm{C} / \mathrm{EBPb}$ drive OPN expression [72]. OPN expression in bleomycin-treated senescent fibroblasts is independent of p53 and $\mathrm{Rb}$ [68], but our results show that the IER2-induced SASP, including OPN expression, is p53 dependent in melanoma cells, which is consistent with the direct activation of OPN transcription by $\mathrm{p} 53$ [73].

The association between IER2, p53/p21, and poor prognosis in melanoma patients suggests that IER2-induced senescence contributes to tumor progression. This could be mediated at a 
a

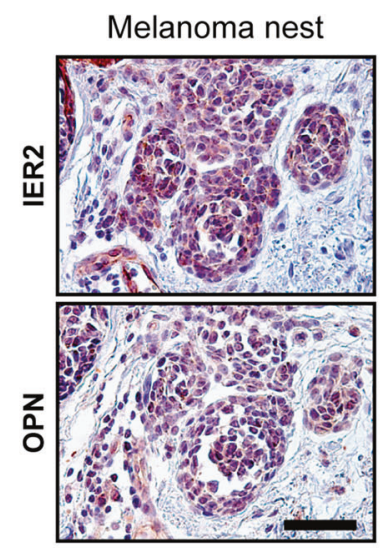

b

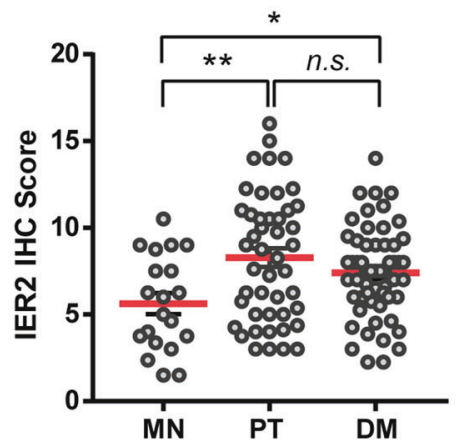



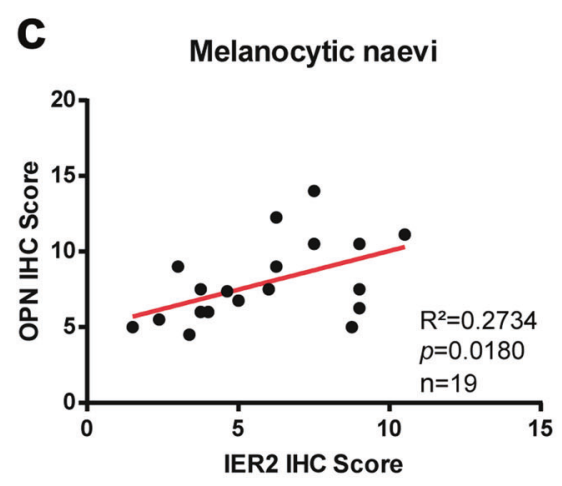

Primary melanoma

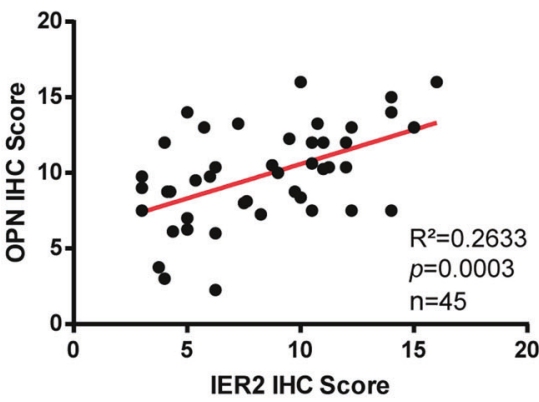

Distant metastases

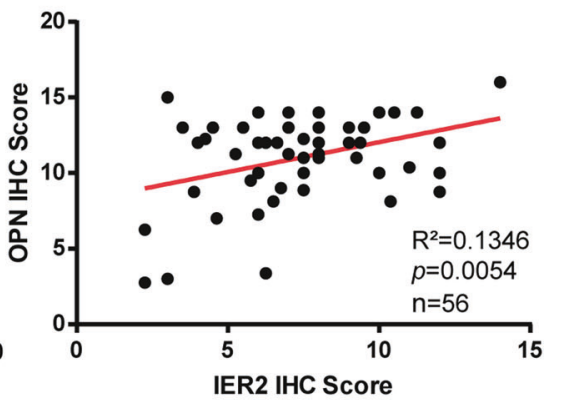

d
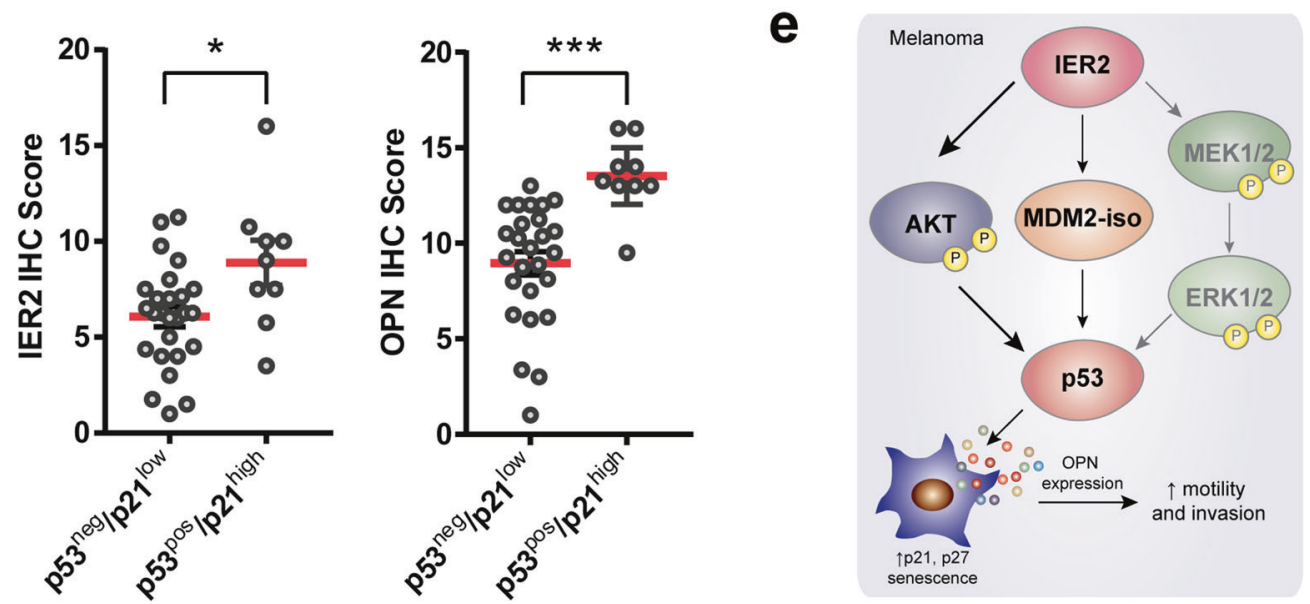

Fig. 8 High IER2 levels are associated with increased osteopontin levels and p53/p21 expression in human melanoma samples. a Representative images of serial sections of melanoma nests (Clark level IV) stained with IER2 and OPN. Scale bar, $50 \mu \mathrm{m}$. b TMA immunohistochemistry (IHC) scores for IER2 (left) and OPN (right) for melanocytic nevi (MN, $n=20)$, primary tumors (PT, $n=46$ for IER2 and 48 for OPN), and distant metastases (DM, $n=56$ for IER2 and 63 for OPN). Data represent mean + SEM. c Correlation analysis of IER2 and OPN expression-based IHC analysis of human melanoma TMAs stratified into melanocytic nevi, primary melanomas, and distant metastases. The coefficient of determination $\left(R^{2}\right)$ of linear regression analysis, the $p$ value of Pearson correlation analysis, and the number of samples analyzed are indicated for each graph. d TMA immunohistochemistry (IHC) scores for IER2 (left) and OPN (right) in specimens stratified according to p53/p21 status (inactive: p5 $3^{\text {neg }} / \mathrm{p} 21^{\text {low }}, n=26$; active: $\mathrm{p} 53^{\mathrm{pos}} / \mathrm{p} 21^{\text {high }}, n=9$ ). e Scheme illustrating molecular functions of IER2 in melanoma. Data represent mean + SEM. n.s. nonsignificant $(p>0.05),{ }^{*} p<0.05,{ }^{* *} p<0.01,{ }^{* * *} p<0.001$. In b and d, statistical significance was determined using an unpaired Student's $t$ test.

number of levels. There is increasing evidence that subpopulations of senescent tumor cells may be able to revert to a proliferative state [74]. Senescent tumor cells that resume proliferation have been reported to be more aggressive [26], and to be reprogramed into self-renewing, tumor-initiating cells [75]. Furthermore, the IER2-induced SASP in the senescent subpopulation of cells could conceivably stimulate the growth and aggressiveness of non-senescent tumor cells. In particular, OPN secreted into the tumor microenvironment has been reported to promote tumor growth and metastasis in a number of ways. Through activating receptors such as integrins and CD44, OPN can foster survival, proliferation, motility, and invasion of tumor cells, and can stimulate angiogenesis [58]. Consistently, we found that OPN in the IER2-induced SASP produced by senescent 
6506

melanoma cells is able to stimulate the motility and invasion of non-senescent melanoma cells in a paracrine manner. This is in line with a large body of prior work demonstrating a pro-invasive effect of OPN on tumor cells, mediated by a diverse set of molecular mechanisms [58]. Furthermore, OPN can also recruit myeloid-derived suppressor cells and other bone marrow-derived cells to the tumor microenvironment and metastatic niches, thereby suppressing anticancer immunity and promoting metastasis [76-78]. Moreover, OPN can reprogram normal fibroblasts into tumor-promoting cancer-associated fibroblasts [79].

IER2 could conceivably induce senescence through several mechanisms. Our data clearly show that IER2-induced senescence and OPN production is p53-dependent and requires nuclear localization of the IER2 protein. This is consistent with a proposed transcriptional regulatory role of IER2 [11], with putative IER2 target genes possibly activating senescence-inducing pathways. IER2 can also regulate the substrate specificity of phosphatase PP2A [12]. As PP2A activity has been implicated in the induction of senescence $[80,81]$, this suggests a possible further mechanism through which IER2 might induce senescence. In addition, our time-lapse data suggest that IER2-induced senescence may be associated with incomplete or delayed cytokinesis (Video S1). Defective cytokinesis can increase p53 levels via proteolytic cleavage of MDM2 [82], induce senescence [83, 84], and result in tetraploidy [85], all of which are features we observed upon continuous induction of IER2 expression. It is, therefore, conceivable that constitutive IER2 expression may perturb cytokinesis and thereby induce senescence. In this regard, we note that the AKT pathway, which we show is activated by IER2, is involved in context-dependent cytokinesis failure [86]. Defective cytokinesis can also result in aneuploidy in cancer cells, which fosters genomic instability that can drive tumorigenesis $[85,87]$ and thus may represent a further mechanism through which IER2-induced senescence might conceivably promote cancer progression if cells are subsequently able to re-enter the cell cycle.

IER2 induces senescence in only a subpopulation of melanoma cells, despite the fact that all cells induced with RSL express IER2 (Fig. 5e). This could conceivably reflect heterogeneity in the melanoma cell populations, yet this seems unlikely, as the IER2inducible cells underwent two rounds of single-cell cloning before experiments were performed. The production of SASP components above a given threshold by individual cells may be decisive, as several SASP components can establish and reinforce the senescence phenotype through autocrine positive feedback loops [88-90]. In addition, recently published single-cell tracking experiments suggest that heterogeneity in the decision of whether or not cells enter senescence is determined by differences in the dynamics of p21 expression at particular cell cycle phases [91]. Similarly, the stochastic induction of senescence has been associated with the kinetics of p53 expression, with pulsed p53 expression resulting in reversible arrest, while continuous p53 expression results in senescence [92]. Thus the stochastic induction of senescence upon continuous IER2 expression that we observed may be a consequence of cell fate decisions that are made in response to the kinetics of expression of key regulatory proteins such as p21 and p53 at particular phases of the cell cycle. This notion would be consistent with the observation that a proportion of sorted non-senescent cells that have expressed IER2 constitutively over at least two cell cycles can nevertheless still be induced to enter senescence upon continued IER2 induction (Fig. 5f, g).

Our findings may have clinical relevance at a number of levels. We found that increased IER2 expression is associated with high p53/p21 levels in human melanoma samples, which would be consistent with the induction of senescence observed in vitro. Furthermore, IER2 expression is associated with enhanced OPN expression in human melanoma and also correlates with poor prognosis. IER2, the IER2-induced SASP including OPN, as well as
IER2-induced senescent cells themselves may therefore represent therapeutic targets in melanoma. Given the extensive literature documenting the tumor-promoting role of OPN, blocking the activity of the OPN protein or inhibiting activation of its receptors using small molecules have been suggested as possible therapeutic approaches [93]. As OPN has been implicated in fostering chemoresistance, possibly through autophagy or suppressing apoptosis [58], IER2-induced OPN expression may also represent a mechanism that fosters resistance to chemotherapy. Furthermore, senescent cells exhibit resistance to apoptosis [70], and IER2induced senescence may therefore render melanoma cells intrinsically resistant to chemotherapy-induced apoptosis, as well as through the production of OPN in the SASP. This may be relevant to the development of therapy resistance, as transient chemotherapy-induced senescence has been reported to render cancer cells more aggressive if they are able to subsequently reenter the cell cycle $[26,27]$. Together, these observations suggest that targeting IER2-induced senescent melanoma cells may improve therapeutic outcomes. A number of senolytic drugs that aim to clear senescent cells by inducing apoptosis are currently under development, and the first is already in clinical trials [94].

In summary, these data suggest that aberrant activation of the IER2-p53-OPN axis in melanoma represents a pathophysiological mechanism that can contribute to the aggressive behavior of melanoma cells.

\section{MATERIALS AND METHODS}

\section{Cell lines and molecular cloning}

The human melanoma cell lines A375, SK-Mel-28, and HT144 as well as NIH 3 T3 mouse fibroblasts (3T3) and B16-F10 mouse melanoma cells (B16) were all from American Type Culture Collection (ATCC, Manassas, VA, USA). SK-Mel-147 and SK-Mel-23 were from Memorial Sloan Kettering Cancer Center (NY, USA). Mouse melanoma Ret cells [95] were provided by V. Umansky. 67NR mouse mammary carcinoma cells [96] were established by Dr. Fred Miller and kindly provided by E. Lukanidin (Danish Cancer Society, Copenhagen, Denmark). NIH 3T3 RheoSwitch cells (clones 3T3-ind-IER2 $\# 11$, \#19, and \#22) have been described previously by us [31]. All melanoma and fibroblast cell lines were cultivated in DMEM containing $4.5 \mathrm{~g} / \mathrm{l}$ glucose (Gibco, Carlsbad, CA, USA) supplemented with $10 \%$ fetal bovine serum (FBS; Sigma Aldrich, St. Louis, MO, USA) and 1\% penicillin/ streptomycin sulfate (Gibco, Carlsbad, CA, USA). Mel-STV human melanocytes [97] were cultured in DMEM supplemented with 5\% FBS and 1\% penicillin/streptomycin. Melan-a murine melanocytes (Merck, Darmstadt, Germany) were cultured in RPMI 1640 medium (Gibco, Carlsbad, CA, USA) supplemented with $10 \%$ FBS and $200 \mathrm{nM}$ phorbol-12-myristate-13-acetate (AdipoGen, San Diego, CA, USA). Cells were kept at $37^{\circ} \mathrm{C}$ in an atmosphere with $5 \% \mathrm{CO}_{2}$ and $95 \%$ humidity. The human cancer cell lines were authenticated by the vendor. Mycoplasma contamination was routinely checked in the laboratory by PCR analysis and all cell lines used in the study were confirmed to be mycoplasma negative.

The RheoSwitch two-plasmid system for inducible expression of mammalian genes was purchased from New England Biolabs (Ipswich, MA, USA). pCDNA3.1-empty and pcDNA3.1-TP53 were provided by Dr. Takashi Tokino [73]. The pcDNA3.1/V5-His-IER2 plasmid was generated previously [13] by cloning human IER2 cDNA into pcDNA3.1/V5-His empty vector (Invitrogen, Thermo Fischer Scientific, Waltham, MA, USA). All constructs were verified by sequencing.

B16-ind-IER2 \#51, Ret-ind-IER2 \#69, 67NR-ind-IER2 \#37, and 67NR-indIER2 \#82 cell clones were prepared by transfection of RheoSwitch B16pNEBR-R1, Ret-pNEBR-R1, and 67NR-pNEBR-R1 cells with a pNEBR-X1-IER2 plasmid, containing cloned mouse IER2 cDNA [31]. B16-ind-IER2-mNLS \#56 cells were prepared by transfection of RheoSwitch B16-pNEBR-R1 cells with a pNEBR-IER2 plasmid, containing IER2 CDNA mutated in the NLS using the Stratagene QuikChange Site-Directed Mutagenesis Kit (Agilent Technologies, Santa Clara, CA, USA) according to the manufacturer's instructions. All cells were transfected using Lipofectamine2000 (Thermo Fisher Scientific, Waltham, MA, USA) following the manufacturer's instructions, and selected with G418 (500-700 $\mathrm{gg} / \mathrm{ml}$; Roche Applied Science, Penzberg, Germany) and hygromycin $(500 \mu \mathrm{g} / \mathrm{ml}$; Merck, Darmstadt, Germany) as appropriate. Single-cell colonies were expanded and tested for IER2 expression. 
For live cell imaging, 3T3-IER2-H2B-GFP cells were generated as follows. IER2-inducible 3T3 \#11 cells [98] were stably transfected with the pBOSH2B-GFP expression plasmid (BD Pharmingen, New Jersey, USA). Live cell imaging was performed using an Olympus IX50 inverted microscope equipped with an F-View II imaging system and Cell $\wedge \mathrm{P}$ imaging software (Olympus, Shinjuku, Tokyo, Japan).

B16-ind-IER2-OPN-KO \#24, \#28, \#33, and \#36 cells were generated by CRISPR/Cas9-mediated targeting of OPN, following published protocols [99]. Briefly, One-Shot Stbl3 Chemically Competent Escherichia coli cells (Invitrogen, Thermo Fischer Scientific, Waltham, MA, USA) were transformed with pSpCas9(BB)-2A-Puro V2.0 plasmid (Addgene, \#62988), containing three sgRNA pairs, designed at http://crispr.mit.edu/, targeting the mouse osteopontin (Spp1) locus. B16-ind-IER2 \#51 cells were transfected with sequence-verified plasmids and pulse-selected with puromycin for $72 \mathrm{~h}$ (InvivoGen, San Diego, CA, USA). Cells were tested for osteopontin expression using qRT-PCR and Western blotting. The topscoring sgRNA pair (sgRNA-top: $5^{\prime}$-cac cgA AGC TAT CAC CTC GGC CGT T3'; sgRNA-bottom: 5'-aaa CAA CGGC CGAG GTGA TAGC TTC-3') was used to generate single-cell clones.

\section{Chemicals and cell treatments}

Cells were treated with the following reagents at the indicated concentrations. Doxorubicin hydrochloride (Doxo, $2 \mu \mathrm{M}$ ) and camptothecin (CPT, $2 \mu \mathrm{M})$ were purchased from Sigma-Aldrich/Merck (Darmstadt, Germany). Nutlin-3(a) (NU-3, $5 \mu \mathrm{M})$ and Pifithrin-a (PFT-a, $30 \mu \mathrm{M})$ were purchased from Biomol (Hamburg, Germany). RheoSwitch Ligand 1 (RSL, 0.2-30 $\mu \mathrm{M}$ ) was purchased from New England Biolabs (Ipswich, MA, USA) and Exclusive Chemistry Ltd. (Obninsk, Russia). The MEK/ERK inhibitor Selumetinib (AZD6244; MEKi, $1 \mu \mathrm{M}$ ) was purchased from Selleckchem (Münich, Germany) and the AKT inhibitor (AKTi, $1 \mu \mathrm{M}$ ) from Sigma-Aldrich/ Merck, \#A6730 (Darmstadt, Germany). 3T3 cells were irradiated with $30 \mathrm{~J} /$ $\mathrm{m}^{2}$ UV-C $(245 \mathrm{~nm})$ and cells were harvested $1 \mathrm{~h}$ after the irradiation.

\section{SDS-PAGE and Western blotting}

Cells were washed twice with phosphate-buffered saline (PBS), harvested into hot SDS sample lysis buffer (4\% SDS, $125 \mathrm{mM}$ Tris- $\mathrm{HCl}$ pH 6.8, 20\% glycerol in double-distilled $\mathrm{H}_{2} \mathrm{O}$ ) containing Complete Protease Inhibitor Cocktail (Roche Applied Science, Penzberg, Germany), and sonicated using a Soniprep 150 disintegrator (MSE, London, UK). Protein concentration was determined using the BCA Protein Assay Kit (Pierce Biotechnology, IL, Rockford, USA). DTT (100 mM final concentration) and $0.01 \%$ bromphenol blue were added to lysates before separation by SDS-PAGE. The same protein amount $(30-50 \mu \mathrm{g})$ was loaded into each well. Proteins were electrotransferred onto a nitrocellulose membrane (GE Healthcare, Little Chalfont, UK) at $4{ }^{\circ} \mathrm{C}$ overnight using wet transfer. Specific proteins were detected using primary antibodies (overnight incubation at $4{ }^{\circ} \mathrm{C}$ ) followed by horseradish peroxidase-conjugated secondary antibodies $(2-4 \mathrm{~h}$ incubation at $4^{\circ} \mathrm{C}$ ). Peroxidase activity was detected by enhanced chemiluminescence (ECL; Pierce Biotechnology, Rockford, IL, USA). GAPDH, vinculin, or $\beta$-actin were used as loading controls.

To detect secreted osteopontin (sOPN), proteins in $5 \mathrm{ml}$ conditioned media were incubated with $10 \mu \mathrm{l}$ StrataClean Resin (Agilent Technologies, Santa Clara, CA, USA) and rotated for $1-2 \mathrm{~h}$ at $4^{\circ} \mathrm{C}$. After brief centrifugation, the pellet was resuspended in lysis buffer $(125 \mathrm{mM}$ Tris$\mathrm{HCl} \mathrm{pH} \mathrm{6.8,0.2 \%} \mathrm{SDS,} 20 \%$ glycerin, and $1 \times$ Complete Protease Inhibitor Cocktail) and samples were incubated for $5 \mathrm{~min}$ at $95^{\circ} \mathrm{C}$. Lysates were adjusted to $100 \mathrm{mM}$ DTT and $0.01 \%$ bromphenol blue, then $10 \mu \mathrm{g}$ of total protein (measured with the BCA method) were loaded onto SDS-PAGE gels and Western blotted.

The following antibodies were used for immunoblotting: anti-mouse IER2 (clone 1A2, [13]); anti-human IER2 (ARP34401_P050) from Aviva Systems Biology (San Diego, CA, USA); osteopontin (OPN, \#AF808) from R\&D Systems (Mineapolis, MN, USA); vinculin (\#V9131), MDM2 (3G9, 04-1530), and $\boldsymbol{\beta}$-actin (AC-15, \#A5441) from Merck (Darmstadt, Germany); p16 $^{\text {INK4A }}$ (p16, ab189034) and p21 WAF1/Cip1 (p21, EPR3993, ab109199) from Abcam (Cambridge, MA, USA); p27 $^{\text {KIP1 }}$ (p27, F-8, sc-1641), p21 WAF1/ cip1 (p21, C-19, sc-397), ERK1 (ERK, C-16, sc-93), AKT1/2/3 (AKT, H136, sc8312), MDM2 (SMP14, \#sc-965), and p53 (DO-7, sc-47698) from Santa Cruz Biotechnology (Dallas, TX, USA); p53 (1C12, \#2524), p53-pS15 (D4S1H, \#12571), Rb-pS807/811 (D20B12 XP), Rb (D20), AKT-pS473 (587F11, \#4051), AKT-pT308 (D25E6, \#13038), ERK1/2-pT202/pY204 (\#9101), GAPDH (14C10, \#2118), mTOR (\#2972) and mTOR-pS2448 (\#2971) from Cell Signaling Technology (Danvers, MA, USA); and p53-pS392 (FP3.2, \#629501) from BioLegend (San Diego, CA, USA). Anti-rabbit and anti- mouse IgG-HRP secondary antibodies produced in goat, and anti-goat secondary antibody produced in rabbit were purchased from Dako (Hamburg, Germany). Antibodies were diluted in PBS containing $2.5 \%$ skimmed milk and $0.1 \%$ Tween (Carl Roth, Karlsruhe, Germany) according to the respective manufacturer's instructions. Quantification of Western blots was performed in ImageJ/Fiji [100]. Protein expression was calculated as the integrated density of each band normalized to the average of control-treated samples.

\section{Quantitative real-time PCR (qRT-PCR)}

Total RNA was isolated using TRlzol reagent (Thermo Fisher Scientific, Waltham, MA, USA), following the manufacturer's instructions. RNA (1-2 $\mu \mathrm{g})$ was treated with RNase-free DNase I, followed by EDTA deactivation for $10 \mathrm{~min}$ at $65^{\circ} \mathrm{C}$ (both from Thermo Fisher Scientific, Waltham, MA, USA). First-strand CDNA was synthesized with random hexamer primers, using dNTP mix and RevertAid $H$ Minus Reverse transcriptase (all from Thermo Fisher Scientific, Waltham, MA, USA). qRTPCR was performed in a Stratagene M×3500P qPCR machine (Agilent, Santa Clara, CA, USA) using SYBR Select Master Mix containing SYBR Green dye (Applied Biosystems, Foster City, CA, USA). The relative quantity of CDNA was estimated using the $\triangle \triangle C T$ method, and data were normalized to RPLPO or GAPDH.

The following mouse forward and reverse primers, purchased from Metabion (Steinkirchen, Germany), were used for qRT-PCR: IER2: $5^{\prime}$-TAC CTC TCA GCC AAG GTA GA-3', 5'-TCC TCT TGC GTA TCC ATG GG-3'; IL-6: 5'TAC CAC TTC ACA AGT CGG AGG C-3', 5'-CTG CAA GTG CAT CAT CGT TGT TC-3'; CXCL15: 5'-GGT GAT ATT CGA GAC CAT TTA CTG-3', 5'-GCC AAC AGT AGC CTT CAC CCA T-3'; OPN: 5'-GCT TGG CTT ATG GAC TGA GGT C-3', 5'CCT TAG ACT CAC CGC TCT TCA TG-3'; IL23a: 5'-CAT GCT AGC CTG GAA CGC ACA T-3', 5'-ACT GGC TGT TGT CCT TGA GTC C-3'; CCL5: $5^{\prime}$-CCT GCT GCT TTG CCT ACC TCT C-3', 5'-ACA CAC TTG GCG GTT CCT TCG A-3'; TP53: 5'-GCA TGA ACC GCC GAC CTA TCC-3', 5'-CAG GGC AGG CAC AAA CAC GAA C-3'; RPLPO: 5'-GGA CCC GAG AAG ACC TCC TT-3', 5'-GCA CAT CAC TCA GAA TIT CAA TGG-3'.

The following human forward and reverse primers, purchased from Metabion (Steinkirchen, Germany) were used for qRT-PCR: IER2: $5^{\prime}$-AGT GCA GAA AGA GGC ACA GC-3', 5'-ACC TTG GCC GAG AGG TAG AG-3'; OPN: $5^{\prime}$-CTG ACA TCC AGT ACC CTG ATG C-3', 5'-GGC CTT GTA TGC ACC ATT CA3'; TP53: 5'-CAG CAC ATG ACG GAG GTT GT-3', 5'-TCA TCC AAA TAC TCC ACA CGC-3'; GAPDH: 5'-CGA CCA CTT TGT CAA GCT CA-3', 5'-AGG GGT CTA CAT GGC AAC TG-3'.

The data are expressed as the means + SEM from 3 to 5 biological replicates, analyzed in technical duplicates.

\section{RNA interference}

Small interfering RNAs (siRNA) targeting mouse OPN (siOPN, s74322, \#4390771) were purchased from Thermo Fisher Scientific (Waltham, MA, USA). Silencer Select Negative Control No. 1 siRNA (Thermo Fisher Scientific, \#4390843) was used as a control. Mouse Trp53 was targeted using ON-TARGETplus SMARTpool siRNA (L-040642-00-0005) and ONTARGETplus Non-targeting Control Pool siRNA (D-001810-10-05) as control (Horizon Discovery, Cambridge, UK). OPN siRNAs were introduced into the cells using Lipofectamine RNAiMAX (Invitrogen, Carlsbad, CA, USA), while Trp53 siRNAs were transfected at a final concentration of $25 \mathrm{nM}$ using Lipofectamine 2000 (Thermo Fisher Scientific, Waltham, MA, USA), following the manufacturer's instruction.

\section{Cytokine array}

Gene expression was analyzed in three independent experiments using the mouse Cancer Inflammation and Immunity Crosstalk Array (PAMM181Z, Qiagen Sciences, Germantown, MD, USA) according to the manufacturer's instructions.

\section{Indirect immunofluorescence}

Cells grown on glass coverslips were washed with PBS, fixed with $100 \%$ ice-cold methanol (AppliChem, Darmstadt, Germany) for 10 min at $-20^{\circ} \mathrm{C}$, then permeabilized using $0.1 \%$ Triton X-100 (Carl Roth, Karlsruhe, Germany) for $10 \mathrm{~min}$ at room temperature (RT). After washing with PBS, cells were incubated in 10\% FBS/PBS for $30 \mathrm{~min}$ to block unspecific binding. Cells were incubated with IER2 antibody (ARP34401_P050; Aviva Systems Biology, San Diego, CA, USA) diluted 1:500 in blocking solution for $3 \mathrm{~h}$ at RT, then extensively washed with PBS. Incubation with the goat antirabbit AlexaFluor 546 (Thermo Fisher Scientific, Waltham, MA, USA) 
secondary antibody (1:1000) was performed for $1 \mathrm{~h}$ at RT. Cell nuclei were counterstained with $1 \mu \mathrm{g} / \mathrm{ml}$ DAPI (AppliChem, Darmstadt, Germany) for $5 \mathrm{~min}$ at RT, and coverslips were mounted in Fluoromount mounting medium (SouthernBiotech, Birmingham, AL, USA). Fluorescent signals were captured using a Zeiss Axio Imager D1 microscope equipped with an AxioCam MRm camera and AxioVision 4.7 software (Carl Zeiss, Oberkochen, Germany).

\section{Immunohistochemistry}

Formalin-fixed, paraffin-embedded $5 \mu$ m-thick tumor sections were used for immunohistochemical staining. Deparaffinization in Roti-Histol (Carl Roth, Karlsruhe, Germany) and dehydration in $100-70 \%$ EtOH was followed by 30 min heat-induced antigen retrieval (Target Retrieval Solution pH 6.1; Dako, Hamburg, Germany). Endogenous peroxidase was quenched with hydrogen peroxide ( $3 \%, 5 \mathrm{~min}$, Roth, Karlsruhe, Germany), and unspecific antibody binding was blocked using $10 \%$ goat or rabbit serum in 1\% BSA/ PBS for $1 \mathrm{~h}$ at RT. Samples were then incubated with IER2 (ARP34401_P050; 1:500) from Aviva Systems Biology (San Diego, CA, USA); p53 (DO-7; 1:150) and p21 WAF1/Cip1 (p21, C19; 1:800) from Santa Cruz Biotechnology (Dallas, TX, USA), and OPN antibody (AF808; 1:100) from R\&D Systems (Minneapolis, MN, USA) at $4{ }^{\circ} \mathrm{C}$ overnight. After washing $3 x$ with PBS, slides were incubated with biotinylated secondary antibody for $1 \mathrm{~h}$ at RT (Dako, Hamburg, Germany). Antibody staining was detected using the VECTASTAIN ABC kit and the VECTOR NovaRed peroxidase substrate kit (both from Vector Laboratories, Burlingame, CA, USA). Sections were counterstained with hematoxylin (Merck, Darmstadt, Germany). All primary antibodies were titrated and specificity-tested through negative controls (without primary antibody) prior to their use for TMAs. Tumors derived from MMTV-PyMT mice were used as a positive control for the anti-osteopontin antibody. Visualization of melanoma cells was performed by staining against S100B (Abcam, Cambridge, UK) as described [101].

For scoring of IER2-, OPN-, and p21-stained TMAs, a quantity-/intensitybased IHC scoring system was applied, using the following formula: percentage of IER2/OPN positive cells among the S100B-positive cells $(0-4) \times$ intensity score $(0-4)$ (see Fig. S8A). Nuclear positivity for p53 was assessed based on the percentage of p53-positive cells per punch using a $10 \%$ cutoff $(\leq 10 \%$ tumor cells staining = negative, $\geq 10 \%=$ positive $)$ as previously described [102]. Images of stained tumor sections and TMAs sections were captured using a Zeiss Axio Imager Z1 microscope equipped with an AxioCam HRc camera and AxioVision 4.8 software (Carl Zeiss, Oberkochen, Germany). Image acquisition and scoring were performed in a blind fashion by two independent experimenters (L.K. and S.D.S.), in the majority of cases from duplicate stainings. Low-quality IER2- and OPNstained specimens were excluded from the analysis, which resulted in differing total numbers of specimens analyzed. For each sample, the average score of the two experimenters was used.

\section{Flow cytometry and cell sorting}

To analyze cell cycle and ploidy status of 3T3-ind-IER2 \#11, B16-ind-IER2 \#51, B16-ind-IER2-mNLS \#56 cells, and Ret-ind-IER2 \#69 cells, $1.2 \times 10^{5}$ cells were seeded into 6-well plates and treated with three doses of DMSO or $0.2-5 \mu \mathrm{M}$ RSL every $24 \mathrm{~h}$. Cells were detached with PBS $/ 5 \mathrm{mM}$ EDTA $\left(5-10 \mathrm{~min} / 37^{\circ} \mathrm{C}\right)$, resuspended in PBS with $1 \mathrm{mM} \mathrm{MgCl}$, and centrifuged for 3 min at $1200 \mathrm{rpm}$. Pelleted cells were resuspended in $150 \mu \mathrm{l}$ of $10 \% \mathrm{FBS} / \mathrm{PBS}$ and mixed dropwise with ice-cold $70 \% \mathrm{EtOH}$. After overnight incubation at $-20^{\circ} \mathrm{C}$, cells were centrifuged for $5 \mathrm{~min}$ at $1500 \mathrm{rpm}$, resuspended in $250 \mu \mathrm{l} \mathrm{PBS}$ containing $1 \mu \mathrm{l}$ DRAQ5 fluorescent probe $(5 \mathrm{mM}$; Thermo Fisher Scientific, Waltham, MA, USA) and incubated for $20 \mathrm{~min}$ at RT. Cells were diluted 1:1 with PBS and subjected to flow cytometry analysis using a BD FACSCanto \|I (BD Biosciences, Franklin Lakes, NJ, USA). Doublets and dead cells were excluded from the analysis. Flow cytometry data were analyzed using FlowJo 7.6.5 cytometry analysis software (FlowJo, LLC).

To enrich the senescent fraction in IER2-expressing B16 and Ret cells, cells were treated with $3 \times 0.5$ and $5 \mu \mathrm{M}$ RSL, respectively. Six hours after the last RSL treatment, senescent and non-senescent cells were sorted using a BD FACSARIA llu based on forward and sideward scattering, collected in RSL-containing PBS, and immediately processed for qRT-PCR or western blot analysis. In experiments in which cells were treated with either DMSO or RSL also after the cell sorting, $1 \times 10^{5}$ sorted cells were seeded onto a 12-well plate, left to attach overnight, then treated with RSL or DMSO for additional 3 days, and subsequently processed for SA$\beta$-galactosidase staining. After each sorting, the viability and purity of the sorted fractions were evaluated.

\section{Senescence-associated $\boldsymbol{\beta}$-galactosidase activity assay}

Senescence-associated $\beta$-galactosidase (SA- $\beta$-gal) activity was detected as previously described [34]. Briefly, $1 \times 10^{4} \mathrm{cells} / \mathrm{cm}^{2}$ were seeded in triplicate into 12- to 24-well plates. For knockdown experiments, the cells were transfected immediately with siRNA. After overnight attachment, cells were treated daily with either DMSO or $0.25-5.0 \mu \mathrm{M}$ RSL. Six hours after the last dose, cells were washed with PBS, fixed for $15 \mathrm{~min}$ at RT with a $2 \%$ formaldehyde $/ 0.2 \%$ glutaraldehyde solution, then incubated overnight at $37^{\circ} \mathrm{C}$ in a non- $\mathrm{CO}_{2}$ atmosphere with X-Gal staining solution ( $40 \mathrm{mM}$ citric acid $\mathrm{pH} 6.0,5 \mathrm{mM}$ potassium hexacyanoferrate II, $5 \mathrm{mM}$ potassium hexacyanofer-


(Carl Roth, Karlsruhe, Germany). Cells were extensively washed with PBS and imaged with a Leica DMI6000B inverted microscope equipped with a DCF420 C camera and LAS X Core software (Leica Microsystems, Wetzlar, Germany). The percentage of SA- $\beta$-gal-positive cells from total cells was calculated for three biological replicates. Images were captured using a Zeiss Axio Imager Z1 microscope equipped with an AxioCam HRc camera and AxioVision 4.8 software (Carl Zeiss, Oberkochen, Germany).

\section{Proliferation assays}

Proliferation assays were performed using the CyQUANT NF Cell Proliferation Assay Kit (Molecular Probes, Invitrogen/Thermo Fisher Scientific, Waltham, MA, USA). Cells were seeded in a 96-well plate at a density of $1 \times 10^{3}$ cells/well in four biological replicates and treated daily with RSL or an equivalent volume of DMSO for two days. Cell density was measured $4 \mathrm{~h}$ post-seeding (effective "time 0 "), as well as 24 and $48 \mathrm{~h}$ after the first measurement. The assay was performed according to the manufacturer's instructions. Measurement of fluorescence was detected at $530 \mathrm{~nm}$ using the Infinite 200 plate reader (Tecan Group Ltd., Zürich, Switzerland). Data were calculated as the average fold increase in fluorescence at 24 and $48 \mathrm{~h}$, normalized to fluorescence at $0 \mathrm{~h}$.

\section{Cell viability assay}

To determine cell viability after IER2 induction, 3T3-ind-IER2 \#11 cells were treated daily with $0.5 \mu \mathrm{M}$ RSL or an equal volume of DMSO for three consecutive days. Cells were detached $24 \mathrm{~h}$ after the last dose using $0.05 \%$ Trypsin-EDTA (Gibco, Carlsbad, CA, USA), resuspended in the growth medium, stained 1:1 with 0.4\% Trypan Blue solution (Merck, Darmstadt, Germany) and counted with a hemocytometer.

\section{Migration assay}

Cell exclusion zone migration assays were performed in four biological replicates using two-well silicone inserts (Ibidi, Martinsried, Germany). Cell suspension, $4 \times 10^{5}$ cells $/ \mathrm{ml}$ in $70 \mu \mathrm{l}$, were added to each well of the insert and allowed to grow to confluence overnight. Inserts were removed and images captured $0,8,24$, and $30 \mathrm{~h}$ after removal. Cells were treated with RSL or DMSO at $0,8,24 \mathrm{~h}$ post-insert removal.

To assess migration of B16-F10 cells or melanocytes in the presence of conditioned media, B16 IER2 mNLS-inducible cells or IER2-wt-inducible cells with or without the expression of osteopontin were seeded around the inserts $36 \mathrm{~h}$ before removal of the inserts, and subsequently treated twice per day with RSL or the equivalent volume of DMSO. After $24 \mathrm{~h}, 70 \mu \mathrm{l}$ of a $4 \times 10^{5}$ cells $/ \mathrm{ml}$ suspension of B16-F10 parental (non-inducible), Melan-a or Mel-STV cells were added to each well of the insert and allowed to grow to confluence overnight. Inserts were removed. Images were captured $0 \mathrm{~h}$ and 7-32 h after insert removal at 10x magnification using a Leica DMI6000B inverted microscope equipped with a DCF420 C camera and LAS X Core software (Leica Microsystems, Wetzlar, Germany). Wells was marked to ensure that the same area was imaged at each time point. Images were analyzed using the Fiji/ImageJ software [100], and the wound area was determined with the MRI Wound Healing Tool macro (http://dev.mri.cnrs.fr/ projects/imagej-macros/wiki/Wound_Healing_Tool). The migrated area was calculated as the change in wound area.

\section{Transwell invasion assays}

Invasion assays were performed in triplicate using Corning Costar Transwell cell culture inserts with $8 \mu \mathrm{M}$ pores (Sigma-Aldrich/Merck, Darmstadt, Germany). Inserts were coated with $55 \mu \mathrm{l}$ of $0.6-0.8 \mathrm{mg} / \mathrm{ml} \mathrm{High}$ Concentration Corning Matrigel Matrix (Corning, NY, USA), which was allowed to solidify for $4 \mathrm{~h}$ at $37^{\circ} \mathrm{C}$. Each insert was seeded with $6 \times 10^{4}$ cells in a medium containing $1 \%$ FBS, then were allowed to invade toward a medium containing $10 \%$ FBS for $64 \mathrm{~h}$. Cells were treated with $3 \times 0.5 \mu \mathrm{M}$ (IER2-wt and OPN-KOs) or $30 \mu \mathrm{M}$ (IER2-mNLS) RSL or an equivalent volume of DMSO twice per day. For invasion assays with conditioned media, CM was prepared by growing 
cells in a medium containing $1 \%$ FBS for $48 \mathrm{~h}$, and treating the cells with $3 \times 0.5 \mu \mathrm{M}$ (IER2-wt and OPN-KOs) or $30 \mu \mathrm{M}$ (IER2-mNLS) RSL, or an equivalent volume of DMSO. Transwell inserts were coated as mentioned above. Twenty-four-hour prior to seeding cells in transwell inserts, $1 \times$ $10^{5}$ inducible cells were seeded in a medium containing $10 \%$ FBS to the base of the well and treated with RSL or DMSO once per day. Noninducible B16, Melan-a or Mel-STV cells $\left(6 \times 10^{4}\right)$ were seeded onto the transwell membrane in CM with 1\% FBS (Melan-a, Mel-STV cells) or a mixture of CM and fresh medium containing 1\% FBS (1:1, B16 cells) and allowed to invade across the membrane for $48 \mathrm{~h}$.

After the invasion, cells were either fixed with methanol and stained with $0.1 \mathrm{mg} / \mathrm{ml}$ crystal violet or fixed with $70 \%$ ethanol and stained with DAPI $(5 \mu \mathrm{g} / \mathrm{ml})$. Inserts stained with crystal violet were incubated in $10 \%$ acetic acid to extract the crystal violet stain, and optical density was measured at $595 \mathrm{~nm}$. The degree of invasion was calculated as the average fold difference in optical density or normalized DAPI-stained area of RSL treated samples compared to DMSO treated samples.

\section{Soft-agar assay}

For the soft-agar assay, $1.5 \mathrm{ml}$ of $0.5 \%$ Noble Agar (BD Biosciences, Franklin Lakes, NJ, USA) in DMEM were plated into 6-well plates and allowed to solidify at RT for at least $5 \mathrm{~min}$. Soft agar at a concentration of $0.3-0.35 \%$ was prepared by dilution of $2 \%$ Noble Agar in conditioned DMEM medium of B16 IER2-ind \#51 cells treated daily for three consecutive days with either $0.5 \mu \mathrm{M} \mathrm{RSL}$ or an equivalent volume of DMSO. Two millilitre of this dilution containing $1000-5000$ cells $/ \mathrm{ml}$ was layered on top of the bottom agar. Cells were fed twice per week with $500 \mu \mathrm{l} \mathrm{CM}$ and allowed to grow for $2-3$ weeks. Colonies were fixed and stained with $0.005 \%$ crystal violet, $1 \%$ PFA, and $1 \%$ methanol for $1 \mathrm{~h}$, imaged using a Fusion FX Imager (Vilber, Marne-la-Vallée, France), and quantified using ImageJ/Fiji [100].

\section{Clinical data set analysis}

The cBioportal for Cancer Genomics (http://www.cbioportal.org/ [103] was used to access and download the TCGA Skin Cutaneous Melanoma Dataset containing RNA-Seq expression and clinical data of 471 melanoma patients (TCGA, provisional). The cutoff between IER2 ${ }^{\text {high }}$ and IER2 ${ }^{\text {low }}$ tumors was set at a $z$-score of 1.5. The difference between Kaplan-Meier curves was analyzed using the log-rank (Mantel-Cox) test. TP53, BRAF, and NRAS mutational data from whole-exome sequencing from 362 patients were correlated with IER2 expression. Significance was determined using the unpaired Student's $t$ test.

\section{Gene expression analysis}

RNA was isolated with RNAPure, peqGOLD (Peqlab, Erlangen, Germany). RNA was tested by capillary electrophoresis on an Agilent 2100 Bioanalyzer (Agilent Technologies, Santa Clara, CA, USA) and high quality was confirmed. Gene expression profiling was performed using arrays of mouse Mm430_2.0-type from Affymetrix (Thermo Fisher Scientific, Waltham, MA, USA). Biotinylated antisense CRNA was then prepared from $33 \mathrm{ng} / \mu \mathrm{l}$ RNA according to the Affymetrix standard labeling protocol with the GeneChip WT Plus Reagent Kit and the GeneChip Hybridization, Wash and Stain Kit (both from Affymetrix, Santa Clara, USA). Afterward, the hybridization on the chip was performed on a GeneChip Hybridization oven 640 , then dyed in the GeneChip Fluidics Station 450 and thereafter scanned with a GeneChip Scanner 3000. All of the equipment used was from Affymetrix (High Wycombe, UK). A Custom CDF Version 10 with ENTREZ-based gene definitions was used to annotate the arrays [104]. The raw fluorescence intensity values were normalized by applying quantile normalization and RMA background correction. One-way ANOVA was performed to identify differentially expressed genes using the commercial software package SAS JMP10 Genomics, version 4, from SAS (SAS Institute, Cary, NC, USA). A nominal $p$-value was taken as the level of significance. GSEA was used to determine whether defined lists (or sets) of genes exhibit a statistically significant bias in their distribution within a ranked gene list using the software GSEA [35]. Pathways belonging to various cell functions were obtained from public external databases (KEGG, http:// www.genome.jp/kegg; Gene Ontology Consortium, biological processes annotations, http://www.geneontology.org/). All analyses were done using three biological replicates. The microarray data have been deposited in Gene Expression Omnibus (GEO) with accession number GSE181200.

\section{Statistics}

Where appropriate, figure legends define the number of biological replicates $(n)$. Results are represented as the mean + SEM (standard error of the mean). For each in vitro experiment, $n$ represents the number of individual biological replicates. Graphs for qRT-PCR experiments represent data from $n \geq 3$ biological replicates, with each biological replicate being executed in two technical replicates. For TCGA Skin Cutaneous Melanoma Dataset analysis, $n=$ number of individual patients. For melanoma TMAs analysis, $n=$ number of analyzed specimens. For experiments comparing two groups, the significance was evaluated using a two-tailed unpaired Student's $t$ test. Asterisks correspond to $p$-values below the following thresholds: ${ }^{*} p<0.05 ;{ }^{* *} p<0.01 ;{ }^{* * *} p<0.001$; n.s. (non-significant) denotes cases where the significance threshold was not reached $(p>0.05)$. For Kaplan Meier survival analysis, significant differences were determined using the log-rank (Mantel-Cox) test. Linear regression $\left(R^{2}\right)$ analysis was used to assess the correlation between IER2 and OPN expression in clinical samples. Sample sizes were chosen based on previous experience with analogous experiments. Randomization was not applied. All statistics were performed with Microsoft Excel 2010 (Microsoft, Redmond, WA, USA) or GraphPad Prism 7 (GraphPad Software, La Jolla, CA, USA). Microscopy images related to in vitro experiments are representative of three biological replicates.

\section{Study approval}

This study was performed in accordance with the ethical votes of the Medical Ethics Committee of the Medical Faculty Mannheim, University of Heidelberg (permit numbers: 2010-318N-MA and 2014-835R-MA). The study followed the guidelines of the Declaration of Helsinki, and patient identity and pathological specimens remained anonymous in the context of the study.

Human melanoma TMA was generated at the core facility of the National Center for Tumor Diseases, Department of Pathology, University of Heidelberg, as described previously $[105,106]$. Information about the specimens and patients contributing to the TMA can be found in Tables S4 and S5.

\section{DATA AVAILABILITY}

To determine phenotype-specific IER2 gene expression in human melanoma cell lines (Table S2, related to Fig. S2), the "Wagner dataset" (Gene Expression Omnibus accession number GSE8332) and the Heuristic Online Phenotype Prediction (HOPP) algorithm were used $[43,44]$. All other data and/or materials are available from the corresponding author upon request. This work was supported by grants to J.P.S. and J.U. from the Deutsche Forschungsgemeinschaft (DFG, German Research Foundation) - Project number 259332240/RTG 2099, and from the European Union (HEALTH-F22008-201662) under the auspices of the FP7 collaborative project TuMIC.

\section{REFERENCES}

1. Bahrami S, Drablos F. Gene regulation in the immediate-early response process. Adv Biol Regul. 2016;62:37-49.

2. Healy $S$, Khan $P$, Davie JR. Immediate early response genes and cell transformation. Pharm Ther. 2013;137:64-77.

3. Cook SJ, Aziz N, McMahon M. The repertoire of fos and jun proteins expressed during the $\mathrm{G} 1$ phase of the cell cycle is determined by the duration of mitogenactivated protein kinase activation. Mol Cell Biol. 1999;19:330-41.

4. Davie JR, Drobic B, Perez-Cadahia B, He S, Espino PS, Sun JM, et al. Nucleosomal response, immediate-early gene expression and cell transformation. Adv Enzyme Regul. 2010;50:135-45.

5. Dunn KL, Davie JR. Stimulation of the Ras-MAPK pathway leads to independent phosphorylation of histone $\mathrm{H} 3$ on serine 10 and 28. Oncogene. 2005;24:3492-502.

6. Charles $\mathrm{CH}$, Simske JS, Obrien TP, Lau LF. Pip92-a short-lived, growth factorinducible protein in Balb/C 3t3 and Pc12 Cells. Mol Cell Biol. 1990;10:6769-74.

7. Lau LF, Nathans D. Identification of a set of genes expressed during the G0/G1 transition of cultured mouse cells. EMBO J. 1985:4:3145-51.

8. Rollins BJ, Stiles CD. Serum-inducible genes. Adv Cancer Res. 1989;53:1-32.

9. Shimizu N, Ohta M, Fujiwara C, Sagara J, Mochizuki N, Oda T, et al. Expression of a novel immediate early gene during 12-O-tetradecanoylphorbol-13-acetateinduced macrophagic differentiation of $\mathrm{HL}-60$ cells. J Biol Chem. 1991;266:12157-61.

10. Scott JL, Dunn SM, Zeng T, Baker E, Sutherland GR, Burns GF. Phorbol esterinduced transcription of an immediate-early response gene by human $T$ cells is inhibited by co-treatment with calcium ionophore. J Cell Biochem. 1994:54:135-44.

11. Takaya T, Kasatani K, Noguchi S, Nikawa J. Functional analyses of immediate early gene ETR101 expressed in yeast. Biosci Biotechnol Biochem. 2009;73:1653-60. 
12. Ueda $T$, Kohama $Y$, Sakurai H. IER family proteins are regulators of protein phosphatase PP2A and modulate the phosphorylation status of CDC25A. Cell Signal. 2019;55:81-89.

13. Neeb A, Wallbaum S, Novac N, Dukovic-Schulze S, Scholl I, Schreiber C, et al. The immediate early gene ler2 promotes tumor cell motility and metastasis, and predicts poor survival of colorectal cancer patients. Oncogene. 2012;31:3796-806.

14. Hong SK, Dawid IB. FGF-dependent left-right asymmetry patterning in zebrafish is mediated by ler2 and Fibp1. Proc Natl Acad Sci USA. 2009;106:2230-5.

15. Wu W, Zhang $X$, Liao $Y$, Zhang W, Cheng $H$, Deng Z, et al. miR-30c negatively regulates the migration and invasion by targeting the immediate early response protein 2 in SMMC-7721 and HepG2 cells. Am J Cancer Res. 2015; 5:1435-46.

16. Xu Z, Zhu L, Wu W, Liao Y, Zhang W, Deng Z, et al. Immediate early response protein 2 regulates hepatocellular carcinoma cell adhesion and motility via integrin beta1-mediated signaling pathway. Oncol Rep. 2017;37:259-72.

17. Xu X, Zhou W, Chen Y, Wu K, Wang H, Zhang J, et al. Immediate early response protein 2 promotes the migration and invasion of hepatocellular carcinoma cells via regulating the activity of Rho GTPases. Neoplasma. 2020;67:614-22.

18. Wu W, Zhang X, Lv H, Liao Y, Zhang W, Cheng H, et al. Identification of immediate early response protein 2 as a regulator of angiogenesis through the modulation of endothelial cell motility and adhesion. Int J Mol Med. 2015;36:1104-10.

19. He S, Sharpless NE. Senescence in health and disease. Cell. 2017;169:1000-11.

20. Munoz-Espin D, Serrano M. Cellular senescence: from physiology to pathology. Nat Rev Mol Cell Biol. 2014;15:482-96.

21. Coppe JP, Patil CK, Rodier F, Sun Y, Munoz DP, Goldstein J, et al. Senescenceassociated secretory phenotypes reveal cell-nonautonomous functions of oncogenic RAS and the p53 tumor suppressor. PLoS Biol. 2008;6:2853-68.

22. Hoare M, Ito Y, Kang TW, Weekes MP, Matheson NJ, Patten DA, et al. NOTCH1 mediates a switch between two distinct secretomes during senescence. Nat Cell Biol. 2016;18:979-92.

23. Wiley $C D$, Velarde $M C$, Lecot $P$, Liu S, Sarnoski EA, Freund $A$, et al. Mitochondrial dysfunction induces senescence with a distinct secretory phenotype. Cell Metab. 2016;23:303-14

24. Bartkova J, Horejsi Z, Koed K, Kramer A, Tort F, Zieger K, et al. DNA damage response as a candidate anti-cancer barrier in early human tumorigenesis. Nature. 2005;434:864-70.

25. Gorgoulis VG, Vassiliou LV, Karakaidos $P$, Zacharatos $P$, Kotsinas A, Liloglou T, et al. Activation of the DNA damage checkpoint and genomic instability in human precancerous lesions. Nature. 2005;434:907-13.

26. Yang L, Fang J. Tumor cell senescence response produces aggressive variants. Cell Death Discov.2017;3:17049

27. Milanovic M, Fan DNY, Belenki D, Dabritz JHM, Zhao Z, Yu Y, et al. Senescenceassociated reprogramming promotes cancer stemness. Nature. 2018;553:96-100.

28. Coppe JP, Desprez PY, Krtolica A, Campisi J. The senescence-associated secretory phenotype: the dark side of tumor suppression. Annu Rev Pathol. 2010;5:99-118.

29. Eggert T, Wolter K, Ji J, Ma C, Yevsa T, Klotz S, et al. Distinct functions of senescence-associated immune responses in liver tumor surveillance and tumor progression. Cancer Cell. 2016;30:533-47.

30. Angelini PD, Zacarias Fluck MF, Pedersen K, Parra-Palau JL, Guiu M, Bernado Morales $C$, et al. Constitutive HER2 signaling promotes breast cancer metastasis through cellular senescence. Cancer Res. 2013;73:450-8.

31. Wallbaum S, Grau N, Schmid A, Frick K, Neeb A, Sleeman JP. Cell cycle quiescence can suppress transcription from an ecdysone receptor-based inducible promoter in mammalian cells. Biotechniques. 2009;46:433.

32. Karzenowski D, Potter DW, Padidam M. Inducible control of transgene expression with ecdysone receptor: gene switches with high sensitivity, robust expression, and reduced size. Biotechniques. 2005;39:191-2, 194. 196 passim

33. Palli SR, Kapitskaya MZ, Kumar MB, Cress DE. Improved ecdysone receptorbased inducible gene regulation system. Eur J Biochem. 2003;270:1308-15.

34. Dimri GP, Lee X, Basile G, Acosta M, Scott G, Roskelley C, et al. A biomarker that identifies senescent human cells in culture and in aging skin in vivo. Proc Natl Acad Sci USA. 1995;92:9363-7.

35. Subramanian A, Tamayo P, Mootha VK, Mukherjee S, Ebert BL, Gillette MA, et al. Gene set enrichment analysis: a knowledge-based approach for interpreting genome-wide expression profiles. Proc Natl Acad Sci USA. 2005;102: 15545-50.

36. Itahana K, Dimri G, Campisi J. Regulation of cellular senescence by p53. Eur J Biochem. 2001;268:2784-91.

37. Momand J, Zambetti GP, Olson DC, George D, Levine AJ. The mdm-2 oncogene product forms a complex with the $\mathrm{p} 53$ protein and inhibits $\mathrm{p} 53$-mediated transactivation. Cell. 1992;69:1237-45.
38. Ebert R, Benisch P, Krug M, Zeck S, Meissner-Weigl J, Steinert A, et al. Acute phase serum amyloid $A$ induces proinflammatory cytokines and mineralization via toll-like receptor 4 in mesenchymal stem cells. Stem Cell Res. 2015;15:231-9.

39. Damsky WE, Rosenbaum LE, Bosenberg M. Decoding melanoma metastasis. Cancers (Basel). 2010;3:126-63.

40. Budczies J, von Winterfeld M, Klauschen F, Bockmayr M, Lennerz JK, Denkert C, et al. The landscape of metastatic progression patterns across major human cancers. Oncotarget. 2015;6:570-83.

41. Hodis E, Watson IR, Kryukov GV, Arold ST, Imielinski M, Theurillat JP, et al. A landscape of driver mutations in melanoma. Cell. 2012;150:251-63.

42. Sensi M, Nicolini G, Petti C, Bersani I, Lozupone F, Molla A, et al. Mutually exclusive NRASQ61R and BRAFV600E mutations at the single-cell level in the same human melanoma. Oncogene. 2006;25:3357-64.

43. Hoek KS, Schlegel NC, Brafford P, Sucker A, Ugurel S, Kumar R, et al. Metastatic potential of melanomas defined by specific gene expression profiles with no BRAF signature. Pigment Cell Res. 2006;19:290-302.

44. Widmer DS, Cheng PF, Eichhoff OM, Belloni BC, Zipser MC, Schlegel NC, et al. Systematic classification of melanoma cells by phenotype-specific gene expression mapping. Pigment Cell Melanoma Res. 2012;25:343-53.

45. Wagner KW, Punnoose EA, Januario T, Lawrence DA, Pitti RM, Lancaster K, et al. Death-receptor O-glycosylation controls tumor-cell sensitivity to the proapoptotic ligand Apo2L/TRAIL. Nat Med. 2007;13:1070-7.

46. Huun J, Gansmo LB, Mannsaker B, Iversen GT, Ovrebo J, Lonning PE, et al. Impact of the MDM2 splice-variants MDM2-A, MDM2-B and MDM2-C on cytotoxic stress response in breast cancer cells. BMC Cell Biol. 2017;18:17.

47. Evans SC, Viswanathan M, Grier JD, Narayana M, El-Naggar AK, Lozano G. An alternatively spliced HDM2 product increases p53 activity by inhibiting HDM2. Oncogene. 2001;20:4041-9.

48. Dang J, Kuo ML, Eischen CM, Stepanova L, Sherr CJ, Roussel MF. The RING domain of Mdm2 can inhibit cell proliferation. Cancer Res. 2002;62:1222-30.

49. Serrano M, Lin AW, McCurrach ME, Beach D, Lowe SW. Oncogenic ras provokes premature cell senescence associated with accumulation of p53 and p16INK4a. Cell. 1997;88:593-602.

50. Paluncic J, Kovacevic Z, Jansson PJ, Kalinowski D, Merlot AM, Huang ML, et al. Roads to melanoma: Key pathways and emerging players in melanoma progression and oncogenic signaling. Biochim Biophys Acta. 2016;1863:770-84.

51. Astle MV, Hannan KM, Ng PY, Lee RS, George AJ, Hsu AK, et al. AKT induces senescence in human cells via mTORC1 and p53 in the absence of DNA damage: implications for targeting mTOR during malignancy. Oncogene. 2012;31:1949-62.

52. Kolesnichenko $M$, Hong $L$, Liao $R$, Vogt $P K$, Sun $P$. Attenuation of TORC1 signaling delays replicative and oncogenic RAS-induced senescence. Cell Cycle. 2012;11:2391-401.

53. Campisi J. Senescent cells, tumor suppression, and organismal aging: good citizens, bad neighbors. Cell. 2005;120:513-22.

54. Rodier F, Campisi J. Four faces of cellular senescence. J Cell Biol. 2011;192:547-56.

55. Loaiza N, Demaria M. Cellular senescence and tumor promotion: Is aging the key? Biochim Biophys Acta. 2016;1865:155-67.

56. Li JH, Tang Y, Lv J, Wang XH, Yang H, Tang PMK, et al. Macrophage migration inhibitory factor promotes renal injury induced by ischemic reperfusion. J Cell Mol Med. 2019;23:3867-77.

57. Rittling SR, Chambers AF. Role of osteopontin in tumour progression. $\mathrm{Br} \mathrm{J}$ Cancer. 2004;90:1877-81.

58. Zhao H, Chen Q, Alam A, Cui J, Suen KC, Soo AP, et al. The role of osteopontin in the progression of solid organ tumour. Cell Death Dis. 2018;9:356.

59. Haapajarvi T, Pitkanen K, Laiho M. Human melanoma cell line UV responses show independency of p53 function. Cell Growth Differ. 1999;10:163-71.

60. Haluska FG, Tsao H, Wu H, Haluska FS, Lazar A, Goel V. Genetic alterations in signaling pathways in melanoma. Clin Cancer Res. 2006;12:2301s-2307s.

61. Prasad R, Katiyar SK. Down-regulation of miRNA-106b inhibits growth of melanoma cells by promoting G1-phase cell cycle arrest and reactivation of p21/ WAF1/Cip1 protein. Oncotarget. 2014;5:10636-49.

62. Krtolica A, Parrinello S, Lockett S, Desprez PY, Campisi J. Senescent fibroblasts promote epithelial cell growth and tumorigenesis: a link between cancer and aging. Proc Natl Acad Sci USA. 2001;98:12072-7.

63. Zhou Y, Dai DL, Martinka M, Su M, Zhang Y, Campos El, et al. Osteopontin expression correlates with melanoma invasion. J Invest Dermatol. 2005; 124:1044-52.

64. Lin AW, Barradas M, Stone JC, van Aelst L, Serrano M, Lowe SW. Premature senescence involving p53 and p16 is activated in response to constitutive MEK/ MAPK mitogenic signaling. Genes Dev. 1998;12:3008-19.

65. Nogueira V, Park Y, Chen CC, Xu PZ, Chen ML, Tonic I, et al. Akt determines replicative senescence and oxidative or oncogenic premature senescence and sensitizes cells to oxidative apoptosis. Cancer Cell. 2008;14:458-70. 
66. Xu Y, Li N, Xiang R, Sun P. Emerging roles of the p38 MAPK and PI3K/AKT/mTOR pathways in oncogene-induced senescence. Trends Biochem Sci. 2014;39:268-76.

67. Pazolli E, Luo X, Brehm S, Carbery K, Chung JJ, Prior JL, et al. Senescent stromalderived osteopontin promotes preneoplastic cell growth. Cancer Res. 2009;69:1230-9.

68. Pazolli E, Alspach E, Milczarek A, Prior J, Piwnica-Worms D, Stewart SA. Chromatin remodeling underlies the senescence-associated secretory phenotype of tumor stromal fibroblasts that supports cancer progression. Cancer Res. 2012;72:2251-61.

69. Saker M, Lipskaia L, Marcos E, Abid S, Parpaleix A, Houssaini A, et al. Osteopontin, a key mediator expressed by senescent pulmonary vascular cells in pulmonary hypertension. Arterioscler Thromb Vasc Biol. 2016;36:1879-90.

70. Herranz N, Gil J. Mechanisms and functions of cellular senescence. J Clin Invest. 2018;128:1238-46.

71. Herranz N, Gallage S, Mellone M, Wuestefeld T, Klotz S, Hanley CJ, et al. mTOR regulates MAPKAPK2 translation to control the senescence-associated secretory phenotype. Nat Cell Biol. 2015;17:1205-17.

72. Flanagan KC, Alspach E, Pazolli E, Parajuli S, Ren Q, Arthur LL, et al. c-Myb and C/ EBPbeta regulate OPN and other senescence-associated secretory phenotype factors. Oncotarget. 2018;9:21-36.

73. Morimoto I, Sasaki Y, Ishida S, Imai K, Tokino T. Identification of the osteopontin gene as a direct target of TP53. Genes Chromosomes Cancer. 2002;33:270-8.

74. Saleh T, Tyutyunyk-Massey L, Murray GF, Alotaibi MR, Kawale AS, Elsayed Z, et al. Tumor cell escape from therapy-induced senescence. Biochem Pharm. 2019;162:202-12.

75. Milanovic M, Yu Y, Schmitt CA. The senescence-stemness alliance-a cancerhijacked regeneration principle. Trends Cell Biol. 2018;28:1049-61.

76. Kim EK, Jeon I, Seo H, Park YJ, Song B, Lee KA, et al. Tumor-derived osteopontin suppresses antitumor immunity by promoting extramedullary myelopoiesis. Cancer Res. 2014;74:6705-16.

77. McAllister SS, Gifford AM, Greiner AL, Kelleher SP, Saelzler MP, Ince TA, et al. Systemic endocrine instigation of indolent tumor growth requires osteopontin. Cell. 2008;133:994-1005.

78. Sangaletti S, Tripodo C, Sandri S, Torselli I, Vitali C, Ratti C, et al. Osteopontin shapes immunosuppression in the metastatic niche. Cancer Res. 2014;74:4706-19.

79. Sharon Y, Raz Y, Cohen N, Ben-Shmuel A, Schwartz H, Geiger T, et al. Tumorderived osteopontin reprograms normal mammary fibroblasts to promote inflammation and tumor growth in breast cancer. Cancer Res. 2015;75:963-73.

80. Kauko O, O'Connor CM, Kulesskiy E, Sangodkar J, Aakula A, Izadmehr S, et al. PP2A inhibition is a druggable MEK inhibitor resistance mechanism in KRASmutant lung cancer cells. Sci Transl Med.2018;10:eaaq1093.

81. Mannava S, Omilian AR, Wawrzyniak JA, Fink EE, Zhuang D, Miecznikowski JC, et al. PP2A-B56alpha controls oncogene-induced senescence in normal and tumor human melanocytic cells. Oncogene. 2012;31:1484-92.

82. Fava LL, Schuler F, Sladky V, Haschka MD, Soratroi C, Eiterer L, et al. The PIDDosome activates p53 in response to supernumerary centrosomes. Genes Dev. 2017;31:34-45.

83. Panopoulos A, Pacios-Bras C, Choi J, Yenjerla M, Sussman MA, Fotedar R, et al. Failure of cell cleavage induces senescence in tetraploid primary cells. Mol Biol Cell. 2014;25:3105-18.

84. Sadaie M, Dillon C, Narita M, Young AR, Cairney CJ, Godwin LS, et al. Cellbased screen for altered nuclear phenotypes reveals senescence progression in polyploid cells after Aurora kinase B inhibition. Mol Biol Cell. 2015;26:2971-85

85. Lens SMA, Medema RH. Cytokinesis defects and cancer. Nat Rev Cancer. 2019;19:32-45.

86. Celton-Morizur S, Merlen G, Couton D, Margall-Ducos G, Desdouets C. The insulin/Akt pathway controls a specific cell division program that leads to generation of binucleated tetraploid liver cells in rodents. J Clin Invest. 2009;119:1880-7.

87. Levine MS, Holland AJ. The impact of mitotic errors on cell proliferation and tumorigenesis. Genes Dev. 2018;32:620-38.

88. Acosta JC, O'Loghlen A, Banito A, Guijarro MV, Augert A, Raguz S, et al. Chemokine signaling via the CXCR2 receptor reinforces senescence. Cell. 2008;133:1006-18.

89. Kuilman T, Michaloglou C, Vredeveld LC, Douma S, van Doorn R, Desmet CJ, et al. Oncogene-induced senescence relayed by an interleukin-dependent inflammatory network. Cell. 2008;133:1019-31.

90. Wajapeyee N, Serra RW, Zhu X, Mahalingam M, Green MR. Oncogenic BRAF induces senescence and apoptosis through pathways mediated by the secreted protein IGFBP7. Cell. 2008;132:363-74.
91. Hsu CH, Altschuler SJ, Wu LF. Patterns of early p21 dynamics determine proliferationsenescence cell fate after chemotherapy. Cell. 2019;178:361-73 e312.

92. Purvis JE, Karhohs KW, Mock C, Batchelor E, Loewer A, Lahav G. p53 dynamics control cell fate. Science. 2012;336:1440-4.

93. Bandopadhyay M, Bulbule A, Butti R, Chakraborty G, Ghorpade P, Ghosh P, et al. Osteopontin as a therapeutic target for cancer. Expert Opin Ther Targets. 2014;18:883-95.

94. van Deursen JM. Senolytic therapies for healthy longevity. Science. 2019;364:636-7.

95. Kato M, Takahashi M, Akhand AA, Liu W, Dai Y, Shimizu S, et al. Transgenic mouse model for skin malignant melanoma. Oncogene. 1998;17:1885-8.

96. Miller FR, Miller BE, Heppner GH. Characterization of metastatic heterogeneity among subpopulations of a single mouse mammary tumor: heterogeneity in phenotypic stability. Invasion Metastasis. 1983;3:22-31.

97. Gupta PB, Kuperwasser C, Brunet JP, Ramaswamy S, Kuo WL, Gray JW, et al. The melanocyte differentiation program predisposes to metastasis after neoplastic transformation. Nat Genet. 2005:37:1047-54.

98. Wallbaum H, Meins E. No sustainable planning, constructing and operating(still) common praxis in the building industry for a good reason? BauingenieurGermany 2009;84:291-303.

99. Ran FA, Hsu PD, Wright J, Agarwala V, Scott DA, Zhang F. Genome engineering using the CRISPR-Cas9 system. Nat Protoc. 2013;8:2281-308.

100. Schindelin J, Arganda-Carreras I, Frise E, Kaynig V, Longair M, Pietzsch T, et al. Fiji: an open-source platform for biological-image analysis. Nat Methods. 2012;9:676-82.

101. Knappe N, Novak D, Weina K, Bernhardt M, Reith M, Larribere L, et al. Directed dedifferentiation using partial reprogramming induces invasive phenotype in melanoma cells. Stem Cells. 2016;34:832-46.

102. Zlobec I, Steele R, Michel RP, Compton CC, Lugli A, Jass JR. Scoring of p53, VEGF, $\mathrm{BCl}-2$ and APAF-1 immunohistochemistry and interobserver reliability in colorectal cancer. Mod Pathol. 2006;19:1236-42.

103. Gao J, Aksoy BA, Dogrusoz U, Dresdner G, Gross B, Sumer SO, et al. Integrative analysis of complex cancer genomics and clinical profiles using the cBioPortal. Sci Signal. 2013;6:pl1.

104. Dai M, Wang P, Boyd AD, Kostov G, Athey B, Jones EG, et al. Evolving gene/ transcript definitions significantly alter the interpretation of GeneChip data. Nucleic Acids Res. 2005;33:e175.

105. Wagner NB, Weide B, Reith $M$, Tarnanidis K, Kehrel C, Lichtenberger $R$, et al. Diminished levels of the soluble form of RAGE are related to poor survival in malignant melanoma. Int J Cancer. 2015;137:2607-17.

106. Jager K, Larribere L, Wu H, Weiss C, Gebhardt C, Utikal J. Expression of neural crest markers GLDC and ERRFI1 is correlated with melanoma prognosis. Cancers (Basel). 2019;11:76

\section{ACKNOWLEDGEMENTS}

We thank Annette Gruber, Sven Roßwag, Jonathan Elton, and Sayran Arif-Said for excellent technical support. We are grateful to Dr. Takashi Tokino from the Medical University School of Medicine, Japan, for providing the pcDNA3.1-empty and pCDNA3.1-TP53 plasmids. We also gratefully acknowledge Stefanie Uhlig for help with flow cytometry, and Karen Bieback for access to the Tecan Microplate Reader. Prof. Ulrike Stein kindly critically read the paper.

\section{AUTHOR CONTRIBUTIONS}

Conceptualization: J.P.S. and L.K.; Methodology: L.K., R.S., S.W., S.D-S., A.N., N.G., S.T., K.R., W.T. and B.K.G.; Validation: L.K., R.S., A.F., M.R., K.R. and S.D.S.; Formal analysis: L.K., R.S., B.K.G., C.S. and No.G.; Investigation and data curation: L.K., R.S. K.R., S.W., S.D.S., A.F., A.N., N.G., N.C. and B.K.G.; Resources: J.U.; Writing-Original Draft: L.K. and J.P.S.; Writing-review \& editing: J.P.S., L.K., W.T., S.D.-S., J.U., N.G., R.S. and B.K.G. Visualization: L.K., R.S. and B.K.G.; Project administration: W.T.; Supervision: J.P.S. and J. U.; Funding acquisition: J.P.S. and J.U.

\section{FUNDING}

Open Access funding enabled and organized by Projekt DEAL.

\section{COMPETING INTERESTS}

Jochen Utikal is on the advisory board or has received honoraria and travel support from Amgen, Bristol Myers Squibb, GSK, LeoPharma, Merck Sharp and Dohme, Novartis, Pierre Fabre, Roche, outside the submitted work. The remaining authors declare no competing interests. 


\section{ADDITIONAL INFORMATION}

Supplementary information The online version contains supplementary material available at https://doi.org/10.1038/s41388-021-02027-6.

Correspondence and requests for materials should be addressed to Jonathan P. Sleeman.

Reprints and permission information is available at http://www.nature.com/ reprints

Publisher's note Springer Nature remains neutral with regard to jurisdictional claims in published maps and institutional affiliations.
Open Access This article is licensed under a Creative Commons Attribution 4.0 International License, which permits use, sharing, adaptation, distribution and reproduction in any medium or format, as long as you give appropriate credit to the original author(s) and the source, provide a link to the Creative Commons license, and indicate if changes were made. The images or other third party material in this article are included in the article's Creative Commons license, unless indicated otherwise in a credit line to the material. If material is not included in the article's Creative Commons license and your intended use is not permitted by statutory regulation or exceeds the permitted use, you will need to obtain permission directly from the copyright holder. To view a copy of this license, visit http://creativecommons. org/licenses/by/4.0/.

(c) The Author(s) 2021 